\title{
Equilibration and Circulation of Red Sea Outflow Water in the Western Gulf of Aden*
}

\author{
AMY S. BOWER \\ Department of Physical Oceanography, Woods Hole Oceanographic Institution, Woods Hole, Massachusetts
}

WiLLIAM E. JOHNS

Division of Meteorology and Physical Oceanography, Rosenstiel School of Marine and Atmospheric Science, University of Miami, Miami, Florida

DAVID M. FRATANTONI

Department of Physical Oceanography, Woods Hole Oceanographic Institution, Woods Hole, Massachusetts

\section{HARTMut Peters}

Division of Meteorology and Physical Oceanography, Rosenstiel School of Marine and Atmospheric Science, University of Miami, Miami, Florida

(Manuscript received 2 September 2004, in final form 11 March 2005)

\begin{abstract}
Hydrographic, direct velocity, and subsurface float observations from the 2001 Red Sea Outflow Experiment (REDSOX) are analyzed to investigate the gravitational and dynamical adjustment of the Red Sea Outflow Water (RSOW) where it is injected into the open ocean in the western Gulf of Aden. During the winter REDSOX cruise, when outflow transport was large, several intermediate-depth salinity maxima (product waters) were formed from various bathymetrically confined branches of the outflow plume, ranging in depth from 400 to $800 \mathrm{~m}$ and in potential density from 27.0 to $27.5 \sigma_{\theta}$, a result of different mixing intensity along each branch. The outflow product waters were not dense enough to sink to the seafloor during either the summer or winter REDSOX cruises, but analysis of previous hydrographic and mooring data and results from a one-dimensional plume model suggest that they may be so during wintertime surges of strong outflow currents, or about $20 \%$ of the time during winter. Once vertically equilibrated in the Gulf of Aden, the shallowest RSOW was strongly influenced by mesoscale eddies that swept it farther into the gulf. The deeper RSOW was initially more confined by the walls of the Tadjura Rift, but eventually it escaped from the rift and was advected mainly southward along the continental slope. There was no evidence of a continuous boundary undercurrent of RSOW similar to the Mediterranean Undercurrent in the Gulf of Cadiz. This is explained by considering 1) the variability in outflow transport and 2) several different criteria for separation of a jet at a sharp corner, which indicate that the outflow currents should separate from the boundary where they are injected into the gulf.
\end{abstract}

\section{Introduction}

Saline, dense Red Sea Water (RSW) originates in the northern Red Sea because of an excess of evaporation over precipitation, and enters the Gulf of Aden (here-

\footnotetext{
* Woods Hole Oceanographic Institution Contribution Number 11259.
}

Corresponding author address: Dr. Amy S. Bower, MS \#21, Department of Physical Oceanography, Woods Hole Oceanographic Institution, Woods Hole, MA 02543.

E-mail: abower@whoi.edu inafter GOA) in the northwestern Indian Ocean as a dense overflow through the shallow Bab el Mandeb (BAM) Strait (see Fig. 1 for locations; Siedler 1968; Morcos 1970). As RSW descends from the $\sim 150 \mathrm{~m}$ deep Hanish Sill in the northern BAM Strait, less dense, fresher water is entrained, and the mixed product water [which we will call Red Sea Outflow Water (RSOW)], reaches neutral buoyancy at intermediate depths in the western GOA. RSOW continues to mix with the ambient waters as it spreads laterally through the GOA and much of the Indian Ocean, where it is traceable as a mid-depth salinity maximum (Rochford 1964; Wyrtki 1971; Beal et al. 2000). 

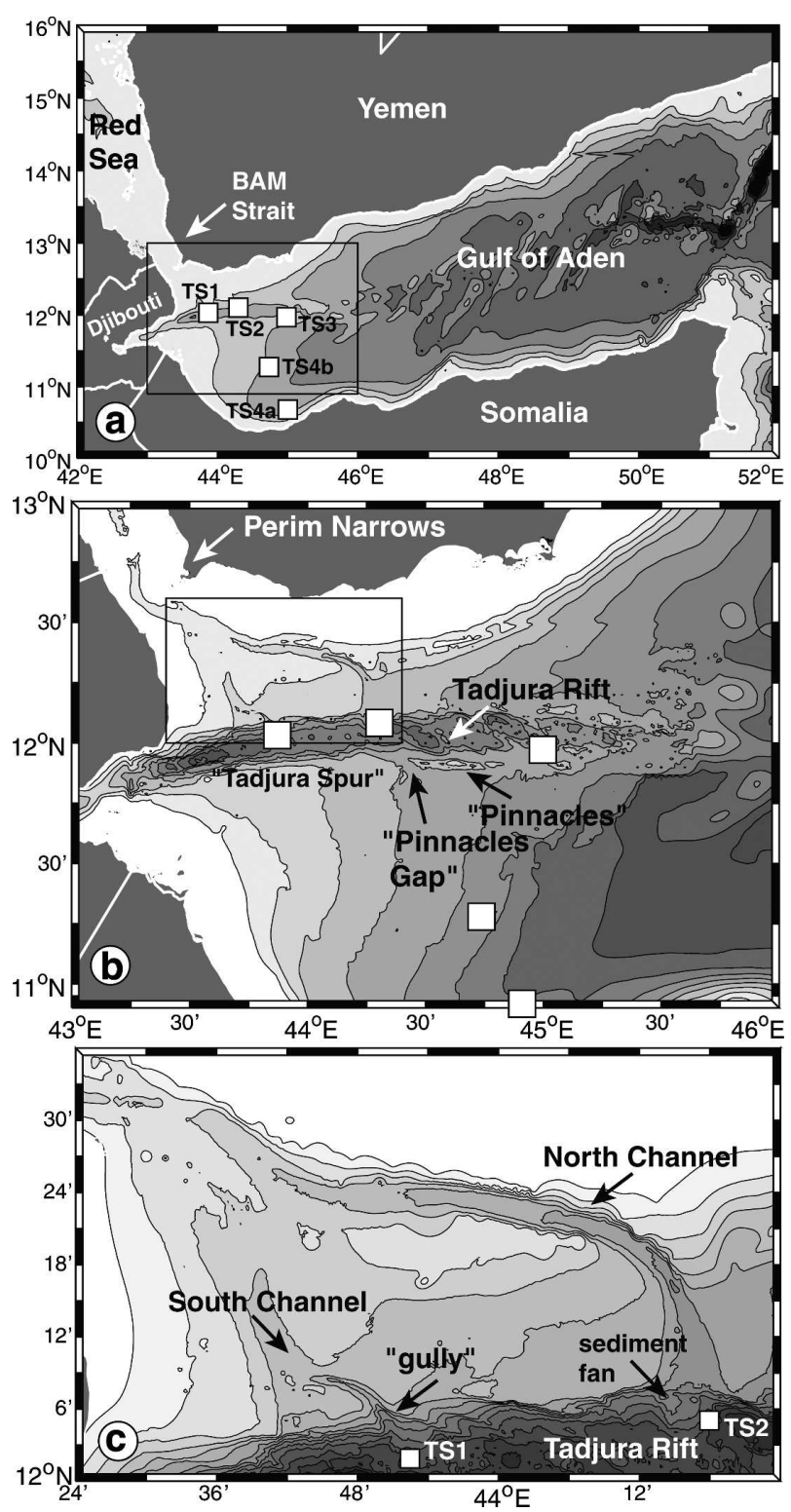

FIG. 1. Charts showing the bathymetry of the Gulf of Aden at various scales. (a) Entire gulf, contour interval $500 \mathrm{~m}$; (b) western gulf, contour interval $200 \mathrm{~m}$; (c) outflow channels, contour interval $100 \mathrm{~m}$. Contours are based on high-resolution, multibeam surveys of the rift and channel regions obtained by French scientists (Hébert et al. 2001), combined with Smith and Sandwell (1997) 2' gridded bathymetry for other regions of the GOA.

Siedler (1969) used the Knudsen relations to estimate the annual mean transport of RSW through BAM Strait to be 0.33 Sverdrup ( $\mathrm{Sv}$; where $1 \mathrm{~Sv} \equiv 10^{6}$ $\mathrm{m}^{3} \mathrm{~s}^{-1}$ ), which was essentially confirmed by Murray and Johns (1997) based on direct velocity observations. For reference, this is about one-third of the mean transport of Mediterranean Water (MW) through the Strait of Gibraltar (see, e.g., Candela 2001). However, during winter, the Red Sea outflow transport is typically about 2 times the annual mean because of monsoon winds and seasonal fluctuations in buoyancy forcing. This seasonal cycle in outflow transport has been recognized for some time (Morcos 1970; Patzert 1974a,b; Osman 1985; Maillard and Soliman 1986), but was quantified with direct velocity observations by Murray and Johns (1997). Outflow transport reaches a maximum $(\sim 0.6 \mathrm{~Sv})$ in winter (October-May), when prevailing monsoon winds over the region are from the south-southeast. At this time of year, the exchange flow has a two-layer structure, with dense, saline RSW flowing out at the bottom, and less dense GOA surface water flowing toward the Red Sea in the upper layer. During summer (June-September), prevailing winds from the north-northwest drive a surface flow out of the Red Sea, and GOA water flows in via an intermediate layer sandwiched between the surface layer and a thin layer of outflowing dense RSW, producing a three-layer exchange flow. Dense outflow transport drops to very low levels in summer (mean $\sim 0.05 \mathrm{~Sv}$ ), and can even stop altogether for brief periods of time (Murray and Johns 1997). Strong intraseasonal variability was also observed by Murray and Johns (1997) during winter, when outflow transport varied between 0.2 and $0.9 \mathrm{~Sv}$ on time scales from several days up to 1 month.

As the dense, saline RSW leaves BAM Strait at Perim Narrows, and begins its descent into the GOA, it divides into two branches, confined by well-defined bathymetric channels: a very narrow $(\sim 5 \mathrm{~km}$ wide), long northern channel (NC) along the Yemeni coast; and a broader, shorter southern channel (SC) closer to Djibouti (see Figs. 1b,c; Siedler 1968). Less dense, fresher water is entrained along these branches as they descend until the RSOW reaches equilibrium with the background stratification in multiple, intermediatedepth layers between 300 and $900 \mathrm{~m}$ (Siedler 1968; Maillard and Soliman 1986; Fedorov and Meshchanov 1988; Bower et al. 2000). The multilayered structure has been attributed to different mixing histories along the two bathymetric channels (Siedler 1968; Bower et al. 2000). Although the existence of multiple product waters has been noted in previous work, the temperature, salinity and density of these layers, and their seasonal variability, have not been well documented because of a lack of high-resolution hydrographic surveys where the outflow equilibrates.

After the RSOW reaches equilibrium in the western GOA, it spreads laterally through the gulf, where its properties are further modified before it enters the open Indian Ocean. Historically, our view of RSOW transformation through the GOA was influenced 
mainly by relatively coarse-resolution along-axis hydrographic sections (Siedler 1968; Wyrtki 1971; Mecking and Warner 1999). While valuable for determining transformation rates through the GOA, these observations provided limited insight into the physical mechanisms that transport RSOW eastward through the gulf. In their analysis of available nonsynoptic historical hydrographic data, and synoptic Air-Deployed Expendable Bathythermograph (AXBT) surveys conducted by the U.S. Naval Oceanographic Office (NAVOCEANO) in the 1990s, Bower et al. (2000) found evidence of a narrow vein of RSOW along the western and southern boundaries of the GOA, highly suggestive of a boundary undercurrent, similar to the Mediterranean Undercurrent in the eastern North Atlantic (Madelain 1970; Ambar and Howe 1979a,b). But without high-resolution density and/or direct velocity observations, the existence of such an undercurrent could not be confirmed.

In 2001, we conducted the Red Sea Outflow Experiment (REDSOX), the first comprehensive field study of the hydrography and circulation of both the descending Red Sea outflow plume, and the equilibrated RSOW in the GOA. The objectives of REDSOX were to 1) describe the pathways and downstream evolution of the descending outflow plumes in the western Gulf of Aden, 2) quantify the processes that control the final depth of the equilibrated RSOW, and 3) identify the transport processes and mechanisms that advect RSOW and its properties through the GOA and into the Indian Ocean. To meet these objectives, two research cruises were carried out, during the seasons of maximum (winter) and minimum (summer) outflow transport (Fig. 2). The new data sets that were collected include two high-resolution hydrographic and direct velocity surveys between Perim Narrows and the mouth of the GOA, trajectories from 44 acoustically tracked subsurface RAFOS floats released in the GOA at the mean depth of the RSOW salinity maximum, shortterm moored hydrographic and velocity measurements in the descending plume, and remote sensing observations of winds, sea surface temperature, and sea surface color.

Previous publications resulting from REDSOX are as follows. Özgökmen et al. (2003) compared observations from the descending plume in the Northern Channel with output from a high-resolution, nonhydrostatic numerical process model and found that the model reproduced some of the general characteristics of the outflow. Peters et al. (2005) and Peters and Johns (2005) first provided an overview of the plume structure during REDSOX, then quantify the turbulent mixing and

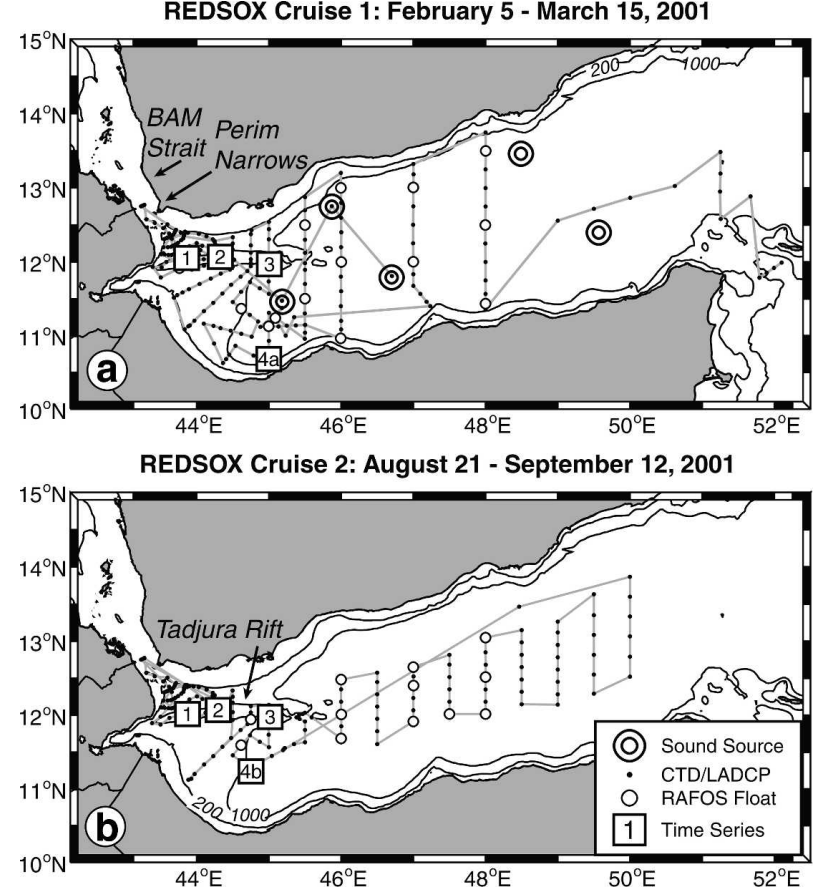

FIG. 2. Charts showing locations of observations collected during (a) winter and (b) summer REDSOX cruises in the Gulf of Aden. See legend for symbol definitions.

entrainment within the plumes in terms of estimated turbulent dissipation rates, vertical turbulent salt flux and interfacial stress. Matt and Johns (2005, manuscript submitted to J. Phys. Oceanogr., hereinafter M05) report details on outflow transports and bulk estimates of entrainment rates. Bower et al. (2002) gave an initial report on the impact of large, deep-reaching mesoscale eddies on RSOW spreading in the GOA. In this paper, we examine the equilibration and circulation of RSOW where the outflow water is first "released" from the confines of the bathymetric channels that have steered its descent, and injected into deep water. We address three specific questions: 1) What are the product water properties and equilibration depths/densities of RSOW in the western GOA during strong (winter) and weak (summer) outflow conditions, and in particular, does RSOW reach the seafloor? 2) How are the initial spreading pathways of the multiple layers of equilibrated RSOW influenced by topography and the background circulation? 3) Does the equilibrated RSOW form a boundary undercurrent similar to other marginal sea outflows upon injection into the open ocean? In the next section, we describe the data used in this study. The results are given in section 3 , followed by discussion and summary in sections 4 and 5, respectively. 


\section{Data and methods}

The new observations discussed here were collected during two cruises in the GOA, the first on the R/V Knorr (5 February-15 March 2001; henceforth, winter cruise) and the second on the R/V Maurice Ewing (21 August-12 September 2001; henceforth, summer cruise; Fig. 2). Observations were made of both the descending outflow plume between Perim Narrows and the edge of the Tadjura Rift (the plume study), and the equilibrated outflow water throughout much of the GOA (the gulf study).

In total, over 200 conductivity-temperature-depthoxygen/lowered acoustic Doppler current profiler $\left(\mathrm{CTDO}_{2} / \mathrm{LADCP}\right)$ profiles were obtained on each cruise (small dots in Fig. 2), using a newly designed and assembled package with a Seabird $911+$ CTD (Johns et al. 2001), a 300-kHz broad band RDI LADCP (Peters and Johns 2005), and a bottle sampler. The CTD/ LADCP package allowed us to observe currents and water properties to depths of $2000 \mathrm{~m}$. Bottle samples were used to calibrate the conductivity and oxygen sensors. Ship-mounted $150-\mathrm{kHz}$, narrowband ADCPs continuously measured current profiles in the upper 300$350 \mathrm{~m}$ along the ship track, complementing the LADCP station data. Accuracy of the LADCP velocity was estimated to be $\pm 0.03 \mathrm{~m} \mathrm{~s}^{-1}$ (Peters and Johns 2005).

In addition to the profile observations, a total of 53 acoustically tracked RAFOS floats (Rossby et al. 1986) were released during REDSOX (Furey et al. 2005). They were tracked using an array of five $780-\mathrm{Hz}$ sources, which have a range of 300-400 km, moored at the positions shown in Fig. 2a. Float position, temperature and pressure were measured four times daily during the 1-yr float missions, providing high-resolution, eddy-resolving float trajectories. The floats were isobaric and ballasted for $650 \mathrm{dbar}$, the mean pressure of the salinity maximum in the GOA (Siedler 1968; Wyrtki 1971).

Thirty-four of the RAFOS floats were the standard single-release (SR) type. They were released over a wide area in the GOA during the two cruises (open circles in Fig. 2) and started their 1-yr missions immediately after launch from the ship. The remaining 19 floats were the dual-release (DR) type, and were initially anchored individually to the seafloor at four "time series" sites (squares in Fig. 2). Every 2 months, one float at each time-release site released its anchor and drifted up to 650 dbar to start its drifting mission, at the end of which it too dropped a ballast weight and returned to the sea surface (a "float park"; Zenk et al. 2000). Except for their method of deployment, the SR and DR floats were identical. Including both SR and DR floats, a total of 27 floats were deployed at the time series sites, with the first release in late February 2001 and the final release in March 2002, for a total of seven releases. Three of the time series sites were located in the Tadjura Rift (TS 1-3), one at each of the exits of the bathymetric channels, and one in the eastern rift (Fig. 2a). The fourth site was located on the continental slope in the southwestern gulf. Following a pirate attack during the summer cruise, TS 4 was relocated farther offshore to site $4 \mathrm{~b}$. All sites were located along the hypothesized path of the RSOW in the GOA.

Four of the 53 REDSOX floats never surfaced, all of them DR floats. The cause of this failure is not known, but since three of these four "no shows" were deployed on the precipitous northern wall of the Tadjura Rift, we speculate that a harsh bottom environment may have caused the failure. Another problem with the RAFOS floats arose because of more-than-expected blocking of sound signals by high ridges throughout the GOA, some of which are taller than indicated on bathymetric maps. Because of these and several other issues (floats hit by ships, floats washed ashore), five other trajectories were not useful, leaving 44 floats returning good data.

In the following analysis, we use a subset of the REDSOX observations to describe the initial equilibration and circulation of RSOW in the far western GOA. These include CTD/LADCP profiles west of $45^{\circ} \mathrm{E}$ and floats released in the western Tadjura Rift.

\section{Results}

\section{a. Bathymetry}

The bathymetry of the western GOA is crucial to the initial spreading pathways of RSOW, and we therefore describe it in detail here. ${ }^{1}$ As seen in Fig. 1a, the GOA is a nearly rectangular basin, about $300 \mathrm{~km}$ wide by 900 $\mathrm{km}$ long, defined by the coastlines of the Arabian Peninsula to the north and the African continent to the south and west. Most of the GOA is generally 2000$2500 \mathrm{~m}$ deep, although it is sliced by many high ridges, some $<1000 \mathrm{~m}$ deep.

\footnotetext{
${ }^{1}$ Key to the success of the REDSOX field program was the acquisition of high-resolution bathymetric data for the western GOA. Through the efforts of S. Swift of the Geology and Geophysics Department at WHOI and P. Huchon of Geosciences Azur, Villefranche-sur-Mer, France, we acquired in advance of the first cruise a high-resolution, multibeam bathymetric dataset from the outflow channels and the Tadjura Rift (Hébert et al. 2001), which proved invaluable in station planning and data interpretation. These data have been used to construct the charts shown in Figs. 1b and 1c and subsequent plots.
} 
The western end of the GOA on the other hand, is characterized by a gradually shoaling continental slope that is deeply cut by the tectonically active Tadjura Rift (Fig. 1b; Hébert et al. 2001). The rift is 15-20 km wide, and has a maximum depth of about $1600 \mathrm{~m}$ near its western end. The tops of the rift walls gradually deepen from west to east, although several narrow, tall ridges are aligned along the tops of the rift walls east of $44^{\circ} \mathrm{E}$, especially along the southern wall (the "Pinnacles"; Fig. 1b). Note that the deep rift is, as well as can be determined, isolated from the rest of the gulf below the 1100-m isobath.

North and west of the rift are the two bathymetric channels, the NC and SC, that originate seaward of Perim Narrows and direct the dense RSW from the strait to the open ocean (Figs. 1b,c). The NC is a 115$\mathrm{km}$ long, 5-km wide trench, and the $\mathrm{SC}$ is shorter and broader. The NC and SC end abruptly at the northern wall of the rift, terminating at about the 800- and 600-m isobaths, respectively (Fig. 1c). Bottom slope along the two channels is on average $\sim 0.005$, while at the channel exits, bottom slope increases dramatically to about $0.05-0.1$. Note the small "gully" east of the main axis of the SC (Fig. 1c), which will be referred to later.

\section{b. Equilibration and vertical distribution of RSOW in the western Gulf of Aden}

The high-salinity Red Sea outflow water was observed descending along the NC and SC as a dense gravity current during both winter and summer REDSOX cruises (Peters et al. 2005). As expected, outflow transport at Perim Narrows was higher during the winter cruise, 0.3 Sv versus $0.06 \mathrm{~Sv}$ during summer (M05). Note that the winter cruise transport was about half of the mean winter value of $0.6 \mathrm{~Sv}$ that was estimated by Murray and Johns (1997), but was within the range of variability that they observed during the winter season. Outflow transport approximately doubled between Perim Narrows and the channel exits (M05), consistent with the temperature-salinity $(T-S)$ analysis and model predictions of Bower et al. (2000).

\section{1) Product WAter Properties}

To illustrate the transition of the outflow from bottom-intensified gravity current to neutrally buoyant intermediate-depth salinity maximum, along-axis sections of salinity and density are plotted in Fig. 3 for the lower part of each channel and extending across the Tadjura Rift, during both winter (upper panels) and summer (lower panels) REDSOX cruises (see Peters et al. 2005 for sections along the entire length of the chan- nels but not including the rift). These sections are not synoptic: each section took 7-10 days to occupy, and outflow currents were observed to change over the sampling period. In particular, the outflow currents in the lower NC during the winter cruise decreased markedly between the time of stations 8-40 and stations 8284 in Fig. 3a (Peters et al. 2005). The most saline and densest outflow water in these sections was observed at the bottom in the NC in winter (Fig. 3a), where maximum density in the lower channel was 27.5-27.6 $\sigma_{\theta}$ and salinity 39.7. Lower values were observed in the SC in winter (Fig. 3b) where maximum density was only about 27.3-27.4 $\sigma_{\theta}$ and salinity 39.3. Much lower values of outflow density and salinity were observed in both channels in summer (Figs. 3c,d).

The hydrographic properties of the most recently equilibrated outflow water were determined by tracking along the channel axes the outflow water with the highest salinity and a positive (heavy) density anomaly (relative to density profiles in the Tadjura Rift) up to the point where the salinity maximum lifts off the bottom and the density anomaly goes to zero. At this point we say that the outflow water is neutrally buoyant, or in gravitational equilibrium with respect to the background stratification. The stations where the outflow first equilibrated are indicated by circles in Fig. 3, and the properties at the depth of the salinity maxima at these stations, or product water properties, are listed in Table 1. In winter, the outflow water equilibrated just as it reached the steep slope at the ends of the NC and SC, where the channels empty into the Tadjura Rift. In summer, equilibration occurred slightly upstream of the channel exits. The NC produces a denser, more saline product water than the SC in winter, with salinity and density of 39.2 and $27.48 \sigma_{\theta}$ as compared with 38.9 and $27.00 \sigma_{\theta}$ from the main axis of the SC. This difference has been attributed to less entrainment along the narrow, confined NC relative to the SC (Siedler 1968; Bower et al. 2000; Peters et al. 2005). In summer, the product waters are much less salty, by 1-2 psu, but they are also cooler by several degrees because of the entrainment of cold GOA water that intrudes into BAM Strait and the Red Sea during this season (see, e.g., Murray and Johns 1997; Smeed 1997). The result is that the summer product waters lie just above the winter product waters in density space (see also Peters et al. 2005).

Vertical sections of salinity and potential density along the axis of the Tadjura Rift during winter and summer (Fig. 4) show how the equilibrated RSOW was distributed relative to the ambient water mass structure. The recently equilibrated outflow waters were embedded in a thicker, intermediate-depth layer of 

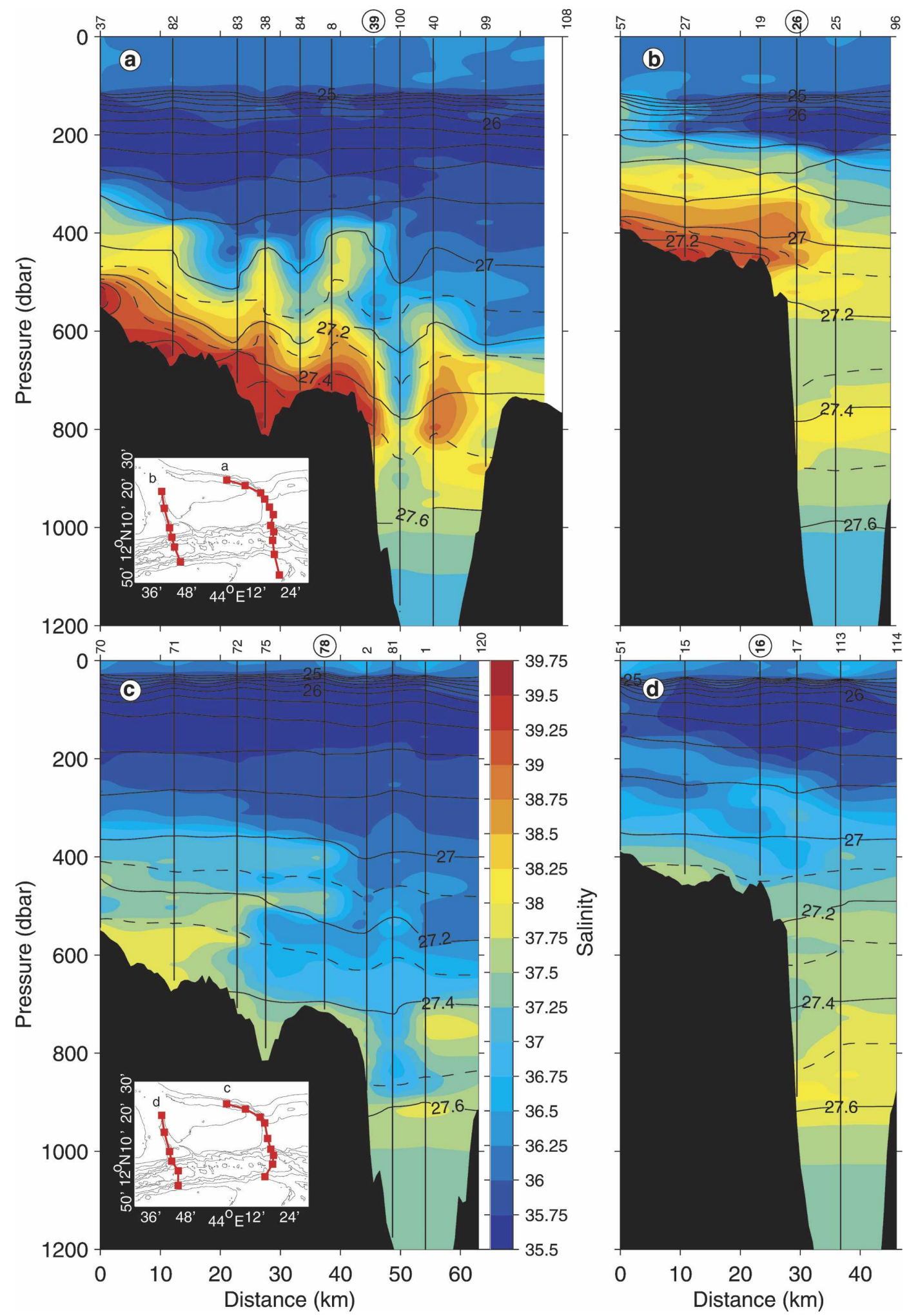

FIG. 3. Vertical sections of salinity (color shading) and potential density (contours) for the lower part of the northern and southern channels (NC and SC) in the western Gulf of Aden, and extending across the Tadjura Rift: (a) winter NC, (b) winter SC, (c) summer NC, and (d) summer SC. Station numbers are indicated along top axes, and locations are plotted in inset charts. Location where outflow first equilibrates is indicated by circled station number. 
TABLE 1. Product water properties of RSOW during REDSOX.

\begin{tabular}{lcccccc}
\hline \hline & \multicolumn{3}{c}{ Winter } & & \multicolumn{2}{c}{ Summer } \\
\cline { 2 - 4 } \cline { 7 - 8 } \cline { 6 - 7 } & $\mathrm{SC}_{\text {main }}$ & $\mathrm{SC}_{\text {gully }}$ & $\mathrm{NC}$ & & $\mathrm{SC}_{\text {main }}$ & $\mathrm{NC}$ \\
\hline$P(\mathrm{dbar})$ & 406 & 575 & 773 & & 419 & 475 \\
$\Theta\left({ }^{\circ} \mathrm{C}\right)$ & 22.5 & 21.7 & 21.7 & & 17.0 & 17.8 \\
$S$ & 38.9 & 38.8 & 39.2 & & 37.6 & 37.4 \\
$\sigma_{\theta}\left(\mathrm{kg} \mathrm{m}^{-3}\right)$ & 27.00 & 27.20 & 27.48 & & 27.10 & 27.20 \\
Station & 26 & 43 & 39 & & 16 & 78
\end{tabular}

moderate salinity. This is especially evident in winter (Fig. 4a), when the recent outflow had equilibrated in the rift with salinities $>38.0$. The winter product waters from the main axes of the SC and NC described above are apparent at station 26 and 39, respectively. There is a third intermediate salinity maximum at station 43 (at about 575 dbar) that is slightly denser (and deeper) than the product waters from the main axis of the SC (at about $400 \mathrm{dbar}$ ). This third product was exiting from the small gully east of the SC's main axis, which probably drains off the densest outflow water from the SC. Note that the two deepest salinity maxima (at stations 43 and 39) lie below the top of the southern wall of the rift (indicated by white hatching), and it will be shown later that they are therefore more bathymetrically confined than the upper maximum at station 26 . In addition to these three primary equilibrated maxima, a very shallow salinity maximum was located at about $125-150$ $\mathrm{m}$ in the western rift during winter (at stations 92,26 , and 43). This outflow water equilibrated well upstream of the channel exits as a result of mixing in the strait itself, and have $\mathrm{S}_{\max }<38.0$.

The basic vertical structure of salinity in the rift was similar during the summer cruise (Fig. 4b) but the maximum salinities were lower and more restricted to the semi-enclosed western end of the rift. The highest salinity in the rift was only $\sim 38$. The salinity maximum observed shallower than $200 \mathrm{dbar}$ in winter was absent altogether in summer.

\section{2) RSOW IN THE DEeP TADJURA RIFT}

In previous studies, it has been suggested that at least some of the Red Sea outflow waters occasionally sink to the bottom of the Tadjura Rift after leaving the NC and SC (Maillard and Soliman 1986; Fedorov and Meshchanov 1988; Mecking and Warner 1999), and that this perhaps happens most often during summer (Maillard and Soliman 1986). This idea was based on a small number of salinity [and chlorofluorocarbon (CFC), in the Mecking and Warner study] profiles, all obtained in the eastern rift at, or east of, $44.3^{\circ} \mathrm{E}$ during summer, that showed the salinity (and CFC) maximum in a thick bottom layer below $1000 \mathrm{~m}$.
The more extensive REDSOX observations reveal that this moderately high-salinity bottom layer is present not only in the eastern rift during summer, as observed previously (see the salinities $>37.0$ below $1000 \mathrm{~m}$ east of $44.3^{\circ} \mathrm{E}$ in Fig. 4b), but that it extends into the western rift where it is overlain by the highersalinity intermediate layer. In fact, the deep rift below about $1100 \mathrm{~m}$ (i.e., below the sill depth of the rift; see section 3a) was entirely filled with a weakly stratified, horizontally homogeneous layer with mean salinity 37.30 and density $27.65 \sigma_{\theta}$. A bottom layer with similar characteristics was also observed in the rift during the REDSOX winter cruise (Fig. 4a), although mean salinity and density were slightly less (37.03 and $27.62 \sigma_{\theta}$ ). The salinities in this bottom layer were at least 1 psu greater than at the same depth outside the rift (Johns et al. 2001), suggesting that the outflow waters somehow feed this deep layer at the bottom of the rift.

The REDSOX observations from the NC and SC show, however, that outflow water was definitely not dense enough to sink to the bottom of the rift during the winter or summer REDSOX cruises. This is illustrated in Figs. 5a and 5b, which show the maximum density of the outflow layer in the channels where the outflow is still a gravity current (which amounts to the density at the bottom of the CTD cast, typically $\leq 10 \mathrm{~m}$ off the bottom) as a function of distance along the channels. Figure 5c shows bottom depth along each channel: the location where the two channels split is indicated by a vertical line, at about $38 \mathrm{~km}$ downstream from Perim Narrows (see Fig. 5d for orientation to the channels). During summer (dashed lines in Figs. 5a,b), there was no outflow water at or downstream of Perim Narrows, in either the $\mathrm{NC}$ or $\mathrm{SC}$, that was as dense as the water in the deep rift: maximum density was only about 27.55 as compared with 27.65 in the deep rift. During winter (solid lines in Figs. 5a,b), the maximum outflow density was considerably higher: it exceeded 27.8 upstream of the channel branching, and exceeded 27.6 in the upper part of the NC. But maximum outflow density dropped below $\sigma_{\theta}=27.6$ about $40 \mathrm{~km}$ upstream of the $\mathrm{NC}$ exit. At the channel exits, the densest water (combining both winter and summer observations) was $27.40-27.50$ in the NC, and 27.05-27.25 in the SC-that is, not dense enough to sink into the deep rift, even if there was no further entrainment or mixing as the water spilled over the rift wall.

Although none of the outflow water in the channels was dense enough to sink into the deep rift during either REDSOX cruise, Fig. 6 shows that only a small increase in the maximum outflow density in the $\mathrm{NC}$ during winter would be necessary to match the density in the bottom of the rift. It shows the maximum 

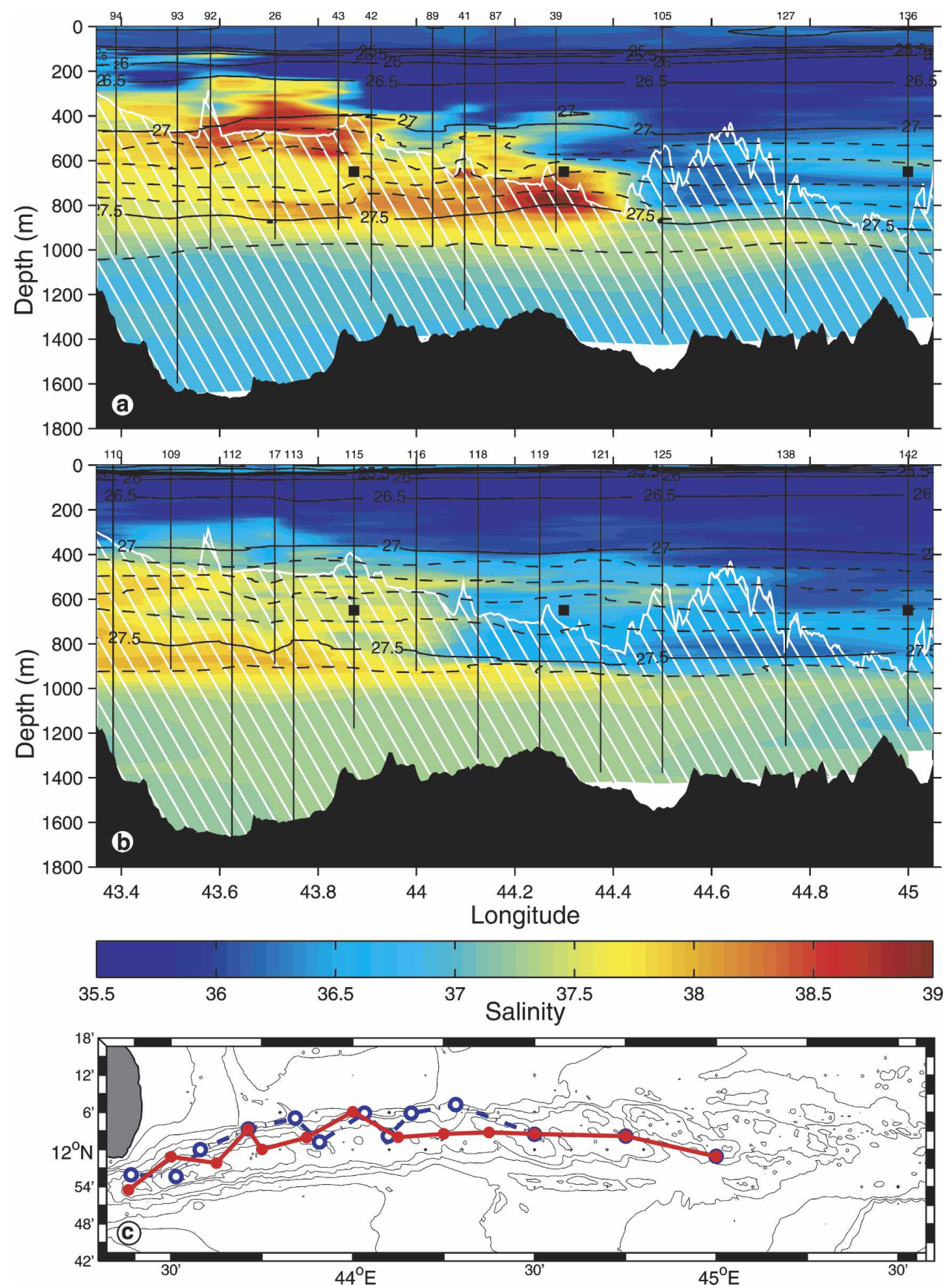

FIG. 4. Vertical sections of salinity (color shading) and potential density (contours) along the axis of the Tadjura Rift during (a) winter and (b) summer REDSOX cruises. (c) Station locations. Black shading indicates depth along the axis of the rift, and white hatching illustrates the depth of the southern rift wall. Black squares show longitude and depth of float release sites within the rift.

density in the $\mathrm{NC}$ during the winter REDSOX cruise as a function of depth along the channel (o's), along with an average winter density profile from the rift (solid line). The densest $\mathrm{NC}$ outflow water observed during REDSOX joins the background stratification at poten- tial density slightly less than $27.5 \sigma_{\theta}$, just $100-200 \mathrm{~m}$ above the weakly stratified bottom layer in the rift, where $\sigma_{\theta}=27.62$.

There is some historical evidence that the outflow water in the NC may at times be denser than observed 

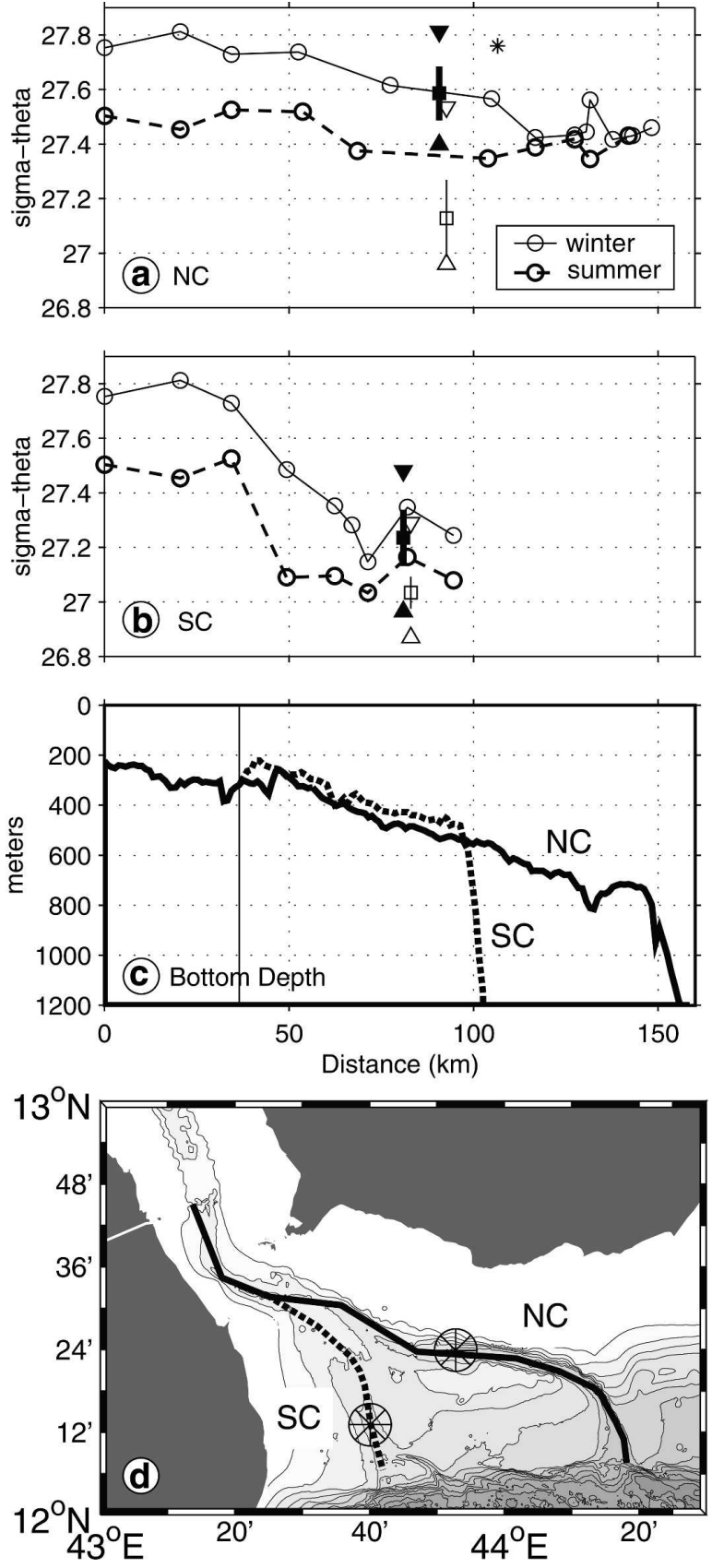

FIG. 5. Maximum potential density of the Red Sea outflow as a function of distance along the (a) northern channel (NC) and (b) southern channel (SC) in the western Gulf of Aden. Solid (dashed) lines are for winter (summer) REDSOX cruises. (c) Bottom depth along channel axes and (d) the locations of the stations in (a) and (b), with channels distinguished by solid (NC) and dashed (SC) lines. The asterisk in (a) shows the maximum potential density observed by Siedler (1968) at his downstream-most station in the NC. The other symbols indicate the mean (squares), minimum (triangles), maximum (inverted triangles), and standard deviation (vertical lines) of potential density $30 \mathrm{~m}$ off the bottom of the channels during winter (filled symbols) and summer (open symbols) from the moored observations of Murray and Johns (1997). Mooring locations are indicated in (d) by a circle-asterisk.

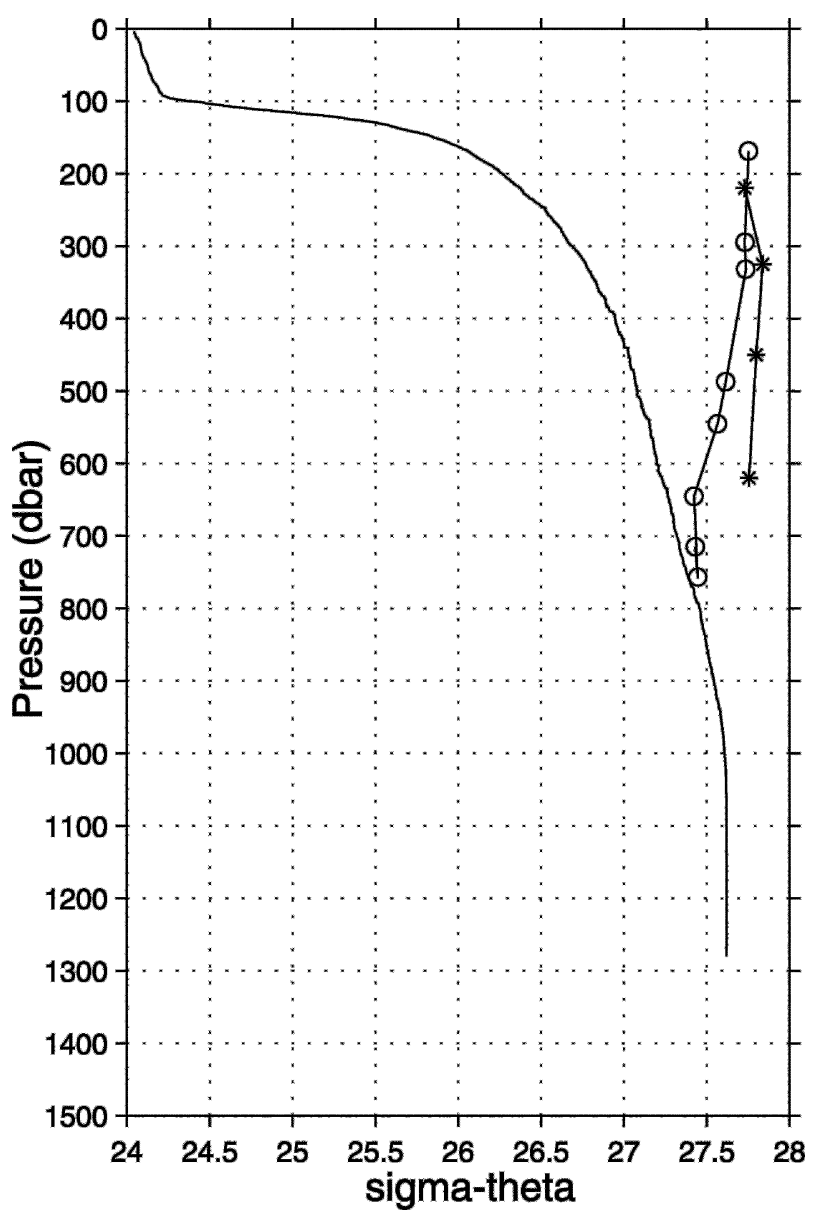

FIG. 6. Mean profile of potential density in the Tadjura Rift (solid line) and the maximum density in the $\mathrm{NC}$ along the descending plume during the REDSOX winter cruise (circles), and Siedler's (1968) winter observations (asterisks).

during REDSOX. In November-December 1964, Siedler (1968) collected temperature-salinity profiles in the NC between Perim Narrows and a location about 30 $\mathrm{km}$ upstream of the $\mathrm{NC}$ exit. The maximum density observed at his four stations (34-37) is plotted in Fig. 6 (asterisks) for comparison with the REDSOX observations. At Perim Narrows, maximum density in 1964 was similar to that during the REDSOX winter cruise, but farther downstream in the NC, higher densities were observed in 1964 than in winter 2001. At Siedler's most downstream station (37), maximum potential density was about 27.76 (height above bottom is unknown), or about $0.2 \mathrm{~kg} \mathrm{~m}^{-3}$ denser than during the REDSOX winter cruise (see also Siedler 1968, his Figs. 21a and 23a). The outflow density at the very end of the NC during the Siedler field program is not known-his observations did not extend to the end of the NC. If the outflow density decreased at the same rate as during REDSOX, the outflow density at the channel exit 
Mooring E (Northern Channel): Second Deployment (1996)
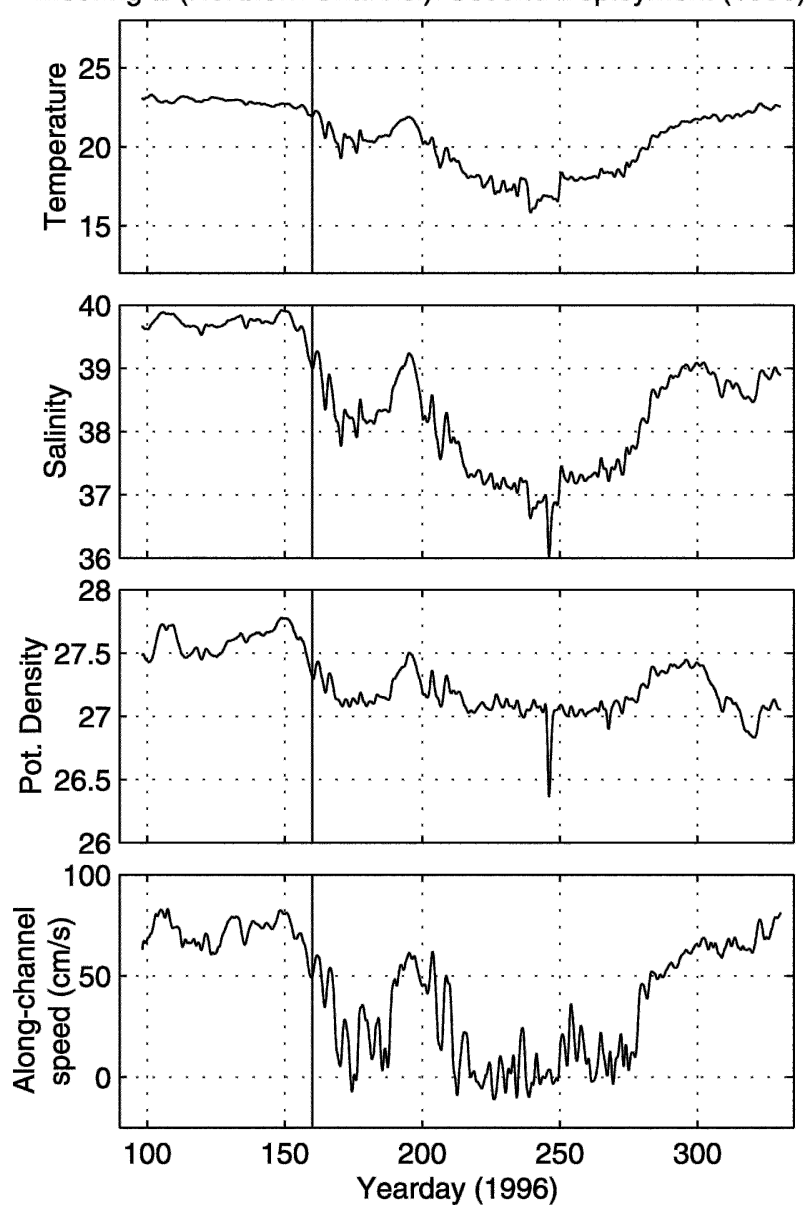

FIG. 7. Time series of (a) temperature, (b) salinity, (c) potential density, and (d) low-pass-filtered (40-h cutoff period) alongchannel speed $30 \mathrm{~m}$ above the bottom of the NC obtained from a mooring deployment in 1996 by Murray and Johns (1997). These data were used to compute the statistics on potential density shown in Fig. 5. Mooring location is shown in Fig. 5d. Only data up to yearday 160 (vertical line) were used to compute correlation between density and outflow speed discussed in text.

might have been around $27.63-27.66 \sigma_{\theta}$, or slightly denser than the water in the deep rift.

Even more dense outflow water was observed in the $\mathrm{NC}$ in the moored measurements of Murray and Johns (1997), which also provide more information on the variability of outflow properties. Current meters were moored $30 \mathrm{~m}$ above the bottom in the $\mathrm{NC}$ and $\mathrm{SC}$ at locations about 92 and $82 \mathrm{~km}$ downstream from Perim Narrows, respectively, during 1995/96 (mooring locations shown in Fig. 5d). For an 8-month period in 1996, the current measurements were accompanied by temperature and salinity measurements using Microcats (Fig. 7 shows an example of the low-passed time series data from the NC only). ${ }^{2}$ Figures $5 \mathrm{a}$ and $5 \mathrm{~b}$ show the mean (squares), standard deviations (vertical lines), minimum (triangles), and maximum (inverted triangles) potential density at $30 \mathrm{~m}$ above the bottom in each channel during summer (open symbols) and winter (solid symbols; summer and winter symbols are offset slightly for visual clarity). Note that while the moored $T-S$ sensors were $30 \mathrm{~m}$ off the bottom, or $\sim 20$ $\mathrm{m}$ above the CTD observations of maximum outflow density, both sets of observations were most likely within the well-mixed bottom layer of the outflow plumes, which is typically $35-120 \mathrm{~m}$ thick (Peters and Johns 2005).

The mean potential density in the $\mathrm{NC}$ from the moored observations in winter is similar to that observed during the REDSOX winter cruise near the same location, 27.6, but much larger densities, approaching 27.8, were also observed on occasion. These highest densities are in line with Siedler's winter observation (asterisk). The mooring mean potential density in the NC in summer is considerably less than was observed during the summer REDSOX cruise: this is likely because during REDSOX-2, there was some (albeit weak) outflow occurring, whereas the summer mooring observations probably include time periods when the outflow was completely shut off, and the bottom of the channel was filled with much lighter GOA water. The same argument may apply to the SC in summer. Note that the maximum density measured at the mooring in the SC was never as dense as the water in the deep rift, even in winter, again implicating the $\mathrm{NC}$ as the only source of outflow water dense enough to possibly sink into the rift. These historical observations thus provide evidence that outflow water in the NC may be dense enough to reach the bottom of the rift on occasion during the winter season, even though this was not the case during the REDSOX winter cruise. Variability of outflow density in relation to other outflow properties will be addressed in more detail in the discussion section below.

\section{c. Horizontal distribution and circulation of RSOW in the western Gulf of Aden}

In this section, we describe the initial lateral spreading pathways of RSOW after it has reached neutral

\footnotetext{
${ }^{2}$ Temperature and salinity were calculated from the sensor data using factory calibrations. Calibration using nearby CTD casts is difficult in light of the very strong horizontal and vertical property gradients and strong time dependence in the plumes. CTD casts during mooring recovery were used to make sure the measurements had not been compromised by biofouling: they indicated that the sensors had drifted less than $0.1^{\circ} \mathrm{C}$ and $0.1 \mathrm{psu}$.
} 
buoyancy in the Tadjura Rift based on CTD, LADCP, and float observations from REDSOX. Figure 8 shows the winter (left panels) and summer (right panels) salinity distributions on three density surfaces in the western GOA, corresponding to the three primary salinity maxima observed during the winter cruise (see Table 1 and Fig. 4). These density surfaces, $\sigma_{\theta}=27.00,27.20$, and 27.48, were observed at nominal depths of 400, 600, and $800 \mathrm{dbar}$. Actual pressure of each surface is shown in Fig. 9. Horizontal velocity vectors (from the LADCP) at the depth of the given density surface at each station, are superimposed, as are the locations of the float time series release sites 1 and 2 (squares). Stations in water depth $<400 \mathrm{~m}$ and stations in the upper NC are not shown.

\section{1) WinTER SURVEY}

At $\sigma_{\theta}=27.00$ (Fig. 8a) in winter, the most saline outflow water was coming from the SC's main axis, with $S=38.75-39.00$ at the channel exit. Speed just upstream of the channel exit was as high as $40 \mathrm{~cm} \mathrm{~s}^{-1}$, but decrease sharply outside the channel exit, to less than $10 \mathrm{~cm} \mathrm{~s}^{-1}$. Salinities greater than 37.75 were observed over the western rift, and greater than 37.50 near the slope south of the rift. This high-salinity outflow water was separated from much fresher water (minimum $S<$ 36.00) to the east by a strong front. Velocities east of the salinity front were as high as $30-40 \mathrm{~cm} \mathrm{~s}^{-1}$, and generally cyclonic. This flow was associated with a large mesoscale eddy centered near $11.5^{\circ} \mathrm{N}, 44.5^{\circ} \mathrm{E}$ (Bower et al. 2002). The doming of this isopycnal surface at the same location (Fig. 9a) is evidence of the eddy's baroclinic structure.

At $\sigma_{\theta}=27.20$ (Fig. 8b), the most saline RSOW originated from the narrow gully at the exit of the SC, with salinities again greater than 38.5 , although high salinities were also observed at this density in the NC. The latter is associated with the top of the denser plume that originates in the NC. Maximum speed in the gully was about $25 \mathrm{~cm} \mathrm{~s}^{-1}$, but as in the main channel, this decreased rapidly at the exit of the gully, to $10 \mathrm{~cm} \mathrm{~s}^{-1}$. The isolating effect of the Tadjura Rift at this level is evident in that the rift is filled with relatively high-salinity water $(S>37.5)$, and a salinity front is located near the rift entrance. Velocities in the rift were less than 15 $\mathrm{cm} \mathrm{s}^{-1}$ and no organized pattern is apparent. Moderately salty water $(S=37.0-37.5)$ is apparent "escaping" from the rift toward the south, and appears to wrap around the cyclonic eddy, which is still visible in the velocity vectors and pressure field (Fig. 9b).

At $\sigma_{\theta}=27.48$ (Fig. 8c), the source of the most saline RSOW switches to the NC, with $\mathrm{S}>39$ at the channel exit. The outflow waters at this level are injected much closer to the rift entrance. Salinity was highest near the NC exit, and exhibits a patchy pattern relative to the western rift. The highest velocities at this level (excluding the NC itself) were associated with a patch of highsalinity outflow water just south of TS 2 . Note the westward intrusion of less saline water at TS 2: this will be discussed again below with respect to the float observations. A patch of high-salinity water $(S \sim 38.5)$ was observed at one station south of the gap between the Tadjura Spur and the Pinnacles, indicative of outflow water exiting the rift to the south. Water of moderate salinity $(S>37)$ was also observed spreading eastward from the rift entrance, unlike at the shallower surfaces. This may be related to the lack of strong westward and southwestward eddy velocities at the deeper level, and the tendency for the east-west rift walls and Pinnacles to direct the deeper RSOW eastward.

\section{2) Summer Survey}

During the summer cruise, salinity in the rift was much lower, as discussed above in the context of the vertical sections. Outflow speeds at the channel exits were also much lower, but still indicating that the outflow was not entirely cut off. At the shallowest level (Fig. 8d) the highest salinity observed was 37.00-37.25 in the far western rift, as compared with greater than 38.5 in winter. Salinity gradients were generally weaker. Velocities away from the channels were also generally weaker, $5-10 \mathrm{~cm} \mathrm{~s}^{-1}$ or less. While the strong cyclonic mesoscale eddy observed during the winter cruise was not evident during summer, a similar, but perhaps weaker, cyclonic feature was located farther to the southeast (Fig. 9d). At the two deeper levels (Figs. 8e,f) the most saline water is confined to the western rift. Note that on the deepest surface (Fig. 8f) salinity in the western rift was actually higher in summer than winter. Velocities in the rift were relatively weak, and again no coherent pattern is apparent.

\section{3) Circulation in the western Gulf of ADEN FROM FLOAT OBSERVATIONS}

The RAFOS floats released in the rift during REDSOX provide information on the evolution of the circulation patterns in the rift, estimates of residence times for RSOW within the rift, and an indication of initial spreading pathways of equilibrated RSOW. All but one of the floats deployed in the rift were released from float time-release sites 1 and 2, located just south of the two channel exits (see Figs. 1b,c). Float tracking within the rift was anticipated to be very difficult because of bathymetric blocking, but some floats were deployed there anyway to get estimates of residence times within the rift. 

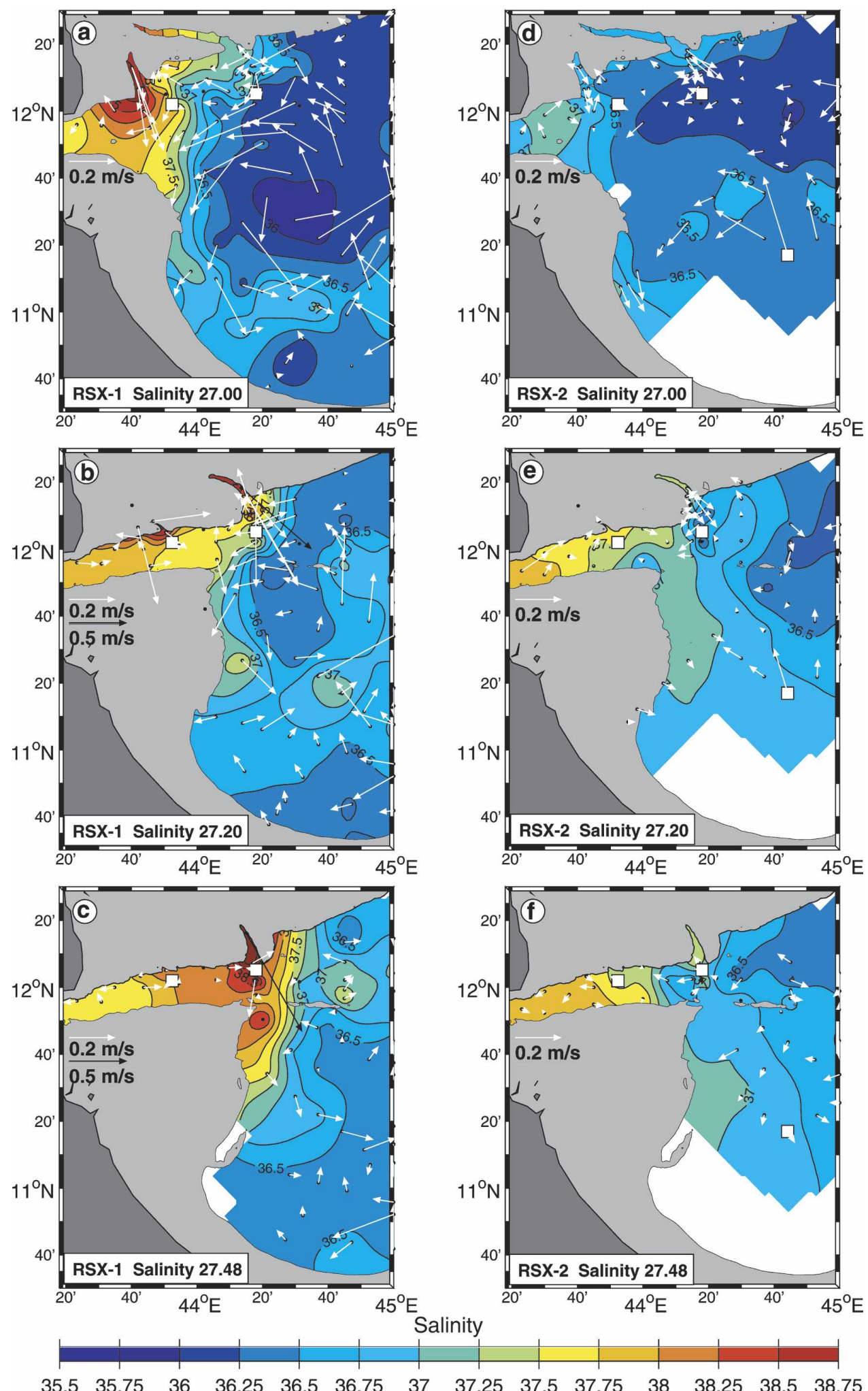

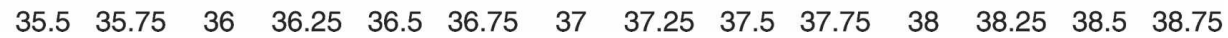

FIG. 8. Maps of salinity (color shading) on three potential density surfaces in the western Gulf of Aden during the (left) winter and (right) summer REDSOX cruises: (a), (d) $27.00 \sigma_{\theta}$; (b), (e) $27.20 \sigma_{\theta}$; and (c), (f) $27.48 \sigma_{\theta}$. Vectors indicate velocity from LADCP at same depth as density surface. Squares indicate float time-release sites 1 and 2. 

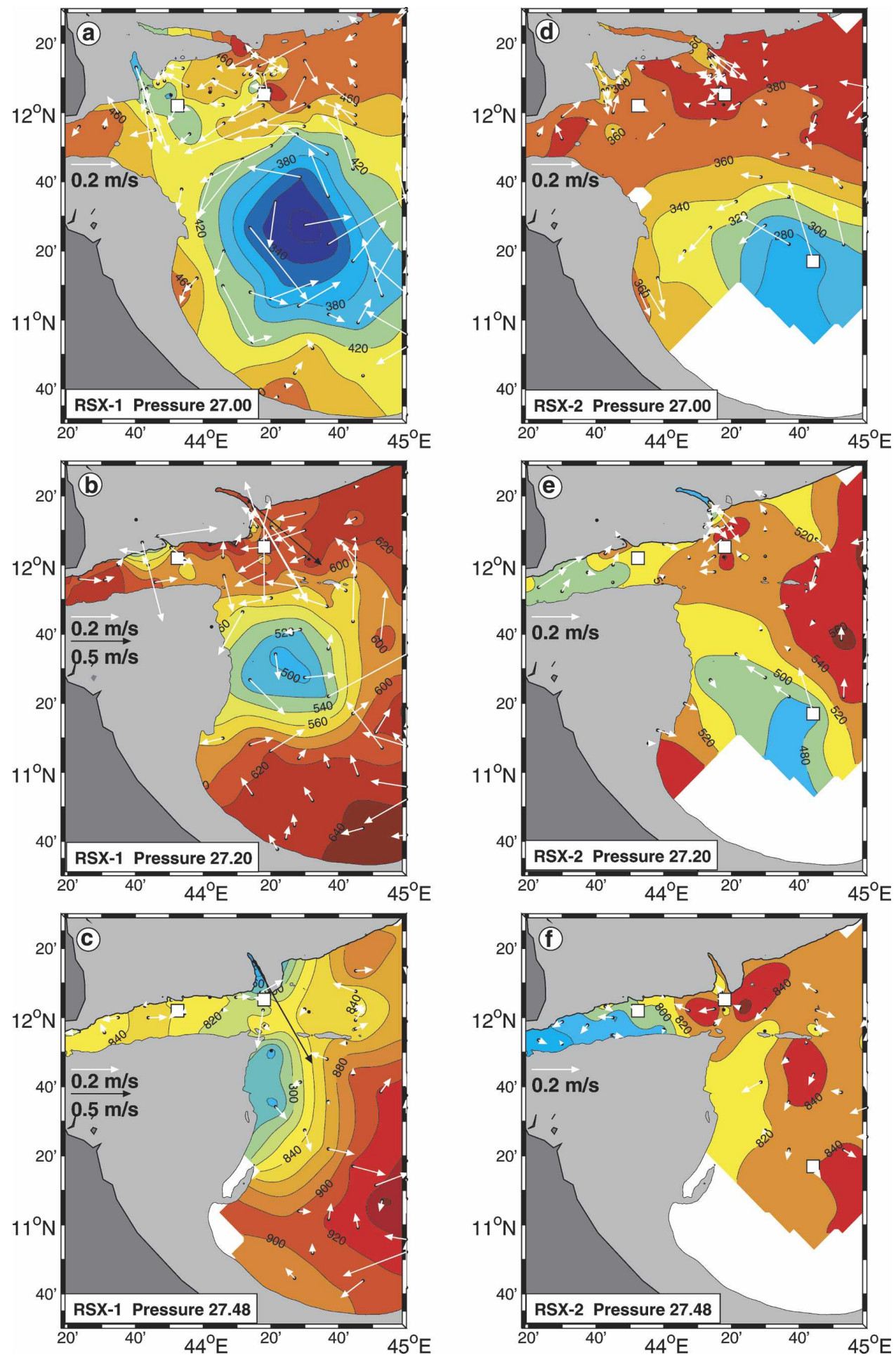

FIG. 9. Same as Fig. 8 but showing maps of pressure of same potential density surfaces.

As it turned out, some tracking was possible within the rift, and in Fig. 10 are shown the first 5 months of trajectories of 10 floats that were at least partially tracked within the rift: four floats from TS 1 (SC exit; left column), five floats from TS 2 (NC exit; right column), and one non-TS float (bottom left panel). A circled " $X$ " marks the release location, and dots along the trajectories are at daily intervals and are color 

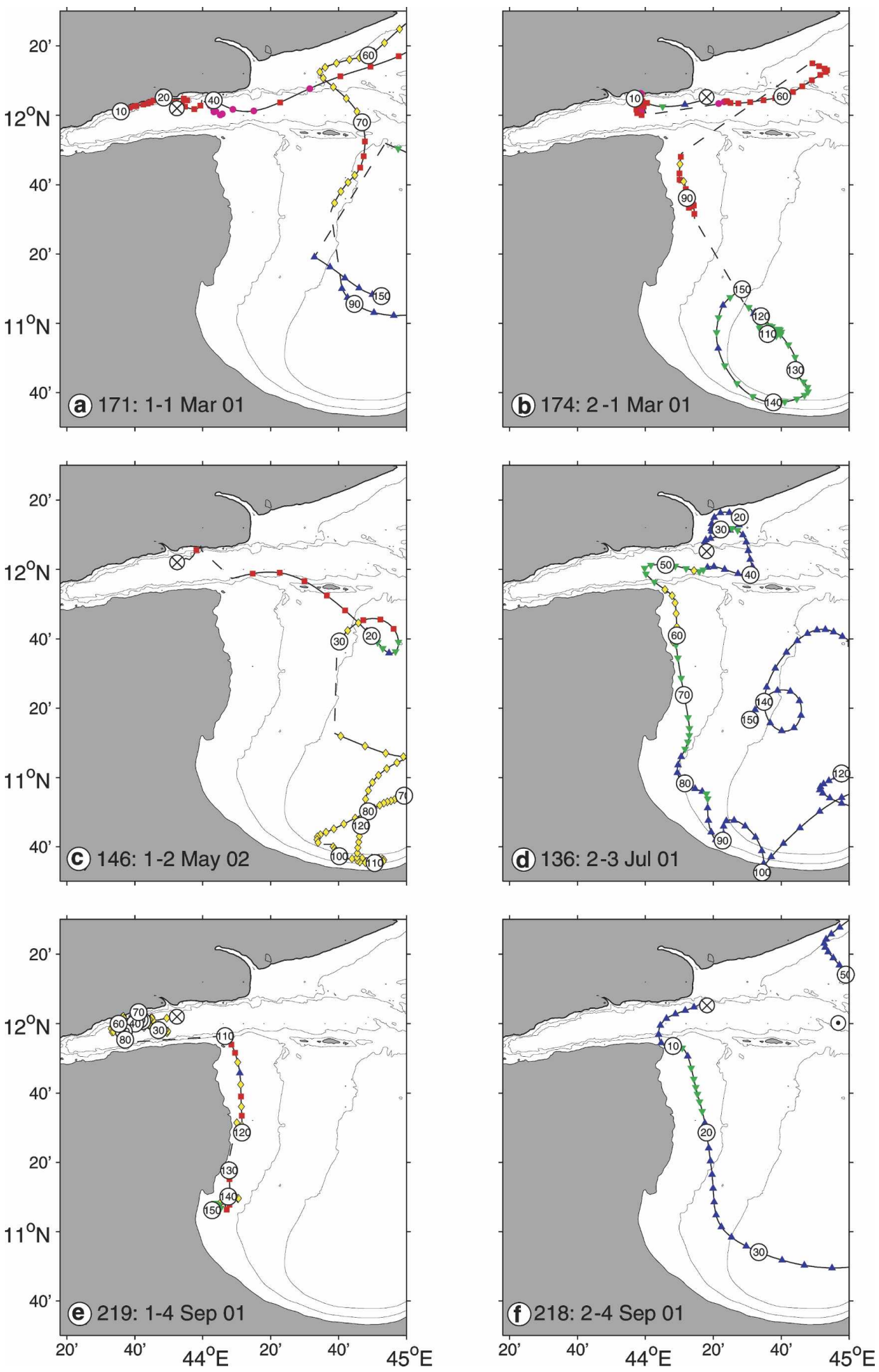

FIG. 10. Trajectories of 10 RAFOS floats released at $\sim 700$ dbar in the Tadjura Rift. Panels are arranged in a quasi-sequential order from top to bottom, with floats released south of the SC shown on the left and floats released at the same time south of the $\mathrm{NC}$ on the right. The exception is (i), which shows the trajectory of a float released in March 2001 near the southern wall of the rift. Colored symbols along float track show daily position, and are numbered every 10 days after release. Colors/symbols indicate temperature ranges along float tracks as follows: magenta/circle $=T>19^{\circ} \mathrm{C}$, red/square $=18<T$ $<19^{\circ} \mathrm{C}$, yellow/diamond $=17<T<18^{\circ} \mathrm{C}$, green/inverted triangle $=16<T<17^{\circ} \mathrm{C}$, and blue/triangles $=$ $T<16^{\circ} \mathrm{C}$. 

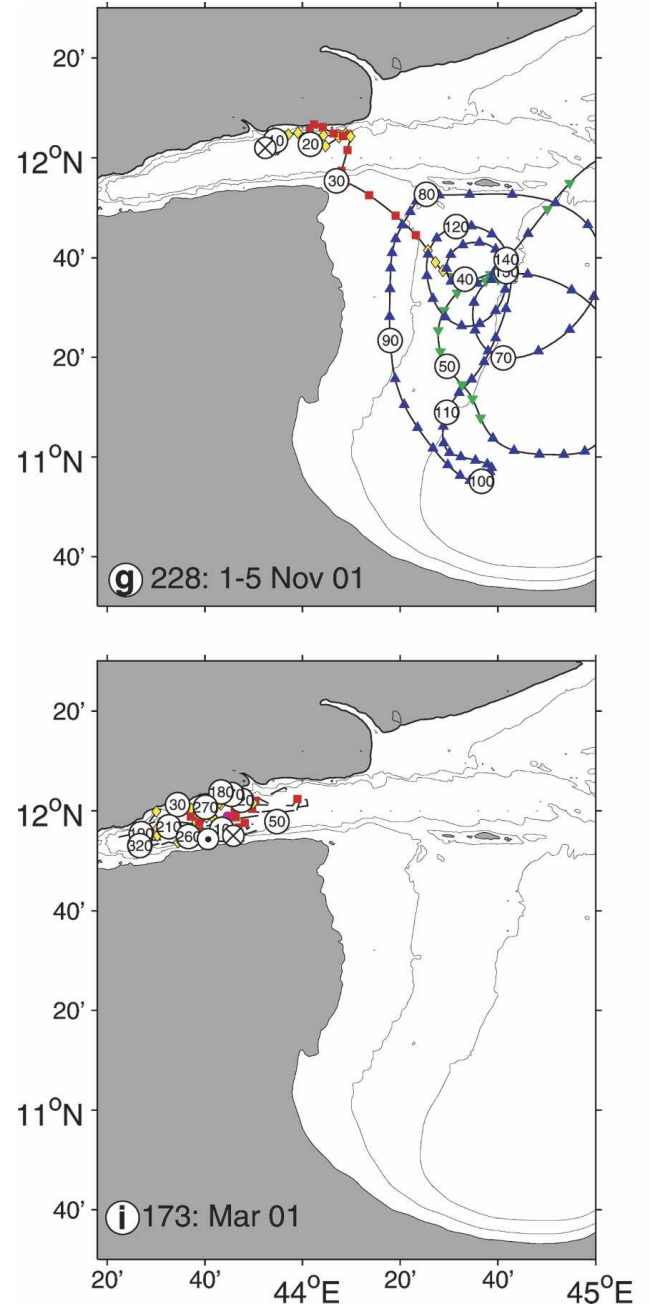
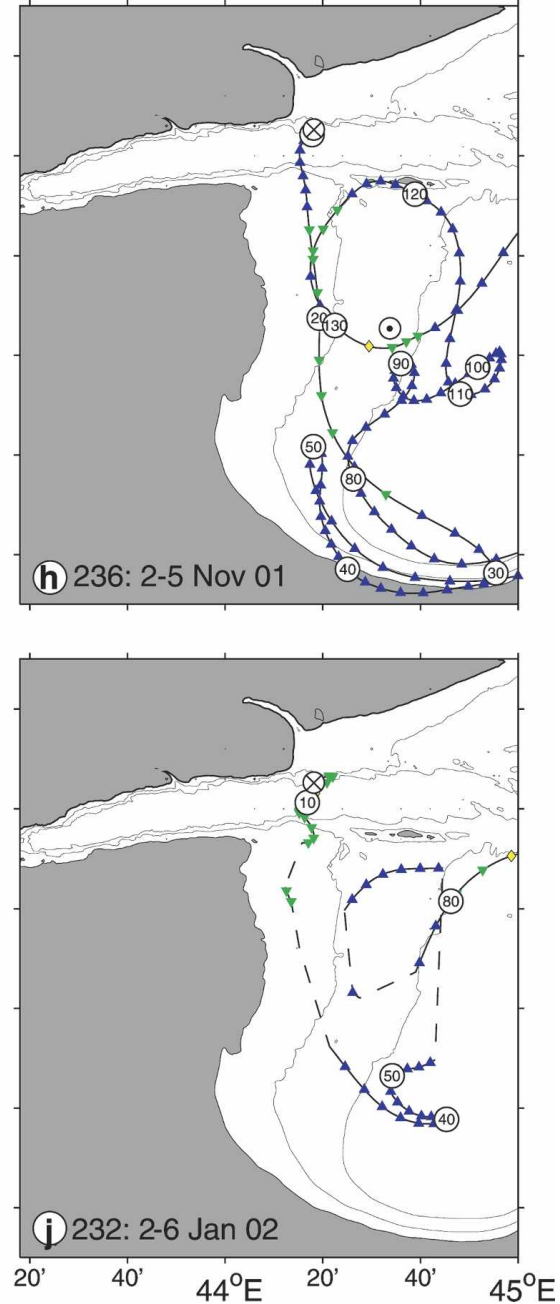

FIG. 10. (Continued)

coded to indicate temperature. Numbers in larger circles indicate days since release. Dashed lines indicate untrackable segments of the trajectories. The float trajectories have been low-pass filtered to eliminate motions with periods less than five days. Table 2 lists the properties of each of these floats for the time they were in the rift. Note that with mean pressures between 650 and $750 \mathrm{dbar}$, the floats occupied the layer between the two deeper salinity maxima in the rift discussed in earlier section. Henceforth individual floats will be referenced according to "TS site-release number"; for example, 1-4 refers to the fourth release from time series site 1 . The plots are arranged in a quasi-sequential order from top to bottom.

After the first release (winter cruise; Figs. 10a,b), floats 1-1 and 2-1 drifted initially westward, deeper into the rift, for about 10 days, with maximum speeds of $10-15 \mathrm{~cm} \mathrm{~s}^{-1}$ (although float 1-1 did a brief transit northeastward immediately after launch). Float $1-1$ ini- tially measured temperatures of $18^{\circ}-19^{\circ} \mathrm{C}$, indicating that it was deployed in slightly diluted outflow water (see Table 1), while $2-1$ initially measured temperatures several degrees cooler, $15^{\circ}-16^{\circ} \mathrm{C}$, which rapidly increased to $19^{\circ}-20^{\circ} \mathrm{C}$ as the float drifted westward. The initially cooler float temperatures are consistent with the CTD observations, which showed a cool, lowsalinity westward intrusion where float $2-1$ was deployed (see station 100 in Fig. 3a and Figs. 8b,c at square south of NC). After the initial westward movement, both floats drifted eastward in the rift until they made cyclonic loops north of the rift axes, then crossed the southern rift wall about 2.5 months after release, and drifted toward the southwestern corner of the gulf. Temperatures along the float tracks were as high as $19^{\circ}-20^{\circ} \mathrm{C}$ near the $\mathrm{NC}$ exit, and decreased to $17^{\circ}-19^{\circ} \mathrm{C}$ as the floats drifted eastward and left the rift. Float 1-1 crossed the southern rift wall east of the Pinnacles, while float 2-1 most likely crossed in the gap between 
TABLE 2. RAFOS floats deployed in Tadjura Rift during REDSOX.

\begin{tabular}{cccccc}
\hline \hline $\begin{array}{c}\text { Release } \\
\text { reference } \\
\text { No. }\end{array}$ & $\begin{array}{c}\text { Float } \\
\text { No. }\end{array}$ & $\begin{array}{c}\text { Date } \\
\text { released }\end{array}$ & $\begin{array}{c}\text { Residence } \\
\text { time in } \\
\text { rift (days) }\end{array}$ & $\begin{array}{c}\text { Mean } T \\
\text { in rift }) \\
\left({ }^{\circ} \mathrm{C}\right)\end{array}$ & $\begin{array}{c}\text { Mean } P \\
(\text { dbar })\end{array}$ \\
\hline \multicolumn{5}{c}{ Time series site 1 } \\
\hline $1-1$ & 171 & 25 Feb 2001 & 71 & 18.5 & 704 \\
$1-2$ & 146 & 1 Mar 2001 & 16 & 18.7 & 673 \\
$1-4$ & 219 & 29 Aug 2001 & 111 & 17.6 & 682 \\
$1-5$ & 228 & 1 Nov 2001 & 34 & 17.8 & 700 \\
\multicolumn{5}{c}{ Time series site 2 } \\
$2-1$ & 174 & 25 Feb 2001 & 83 & 18.4 & 712 \\
$2-3$ & 136 & 1 Jul 2001* & 44 & 15.9 & 718 \\
$2-4$ & 218 & 27 Aug 2001 & 13 & 15.5 & 675 \\
$2-5$ & 236 & 1 Nov 2001 & 15 & 14.4 & 718 \\
$2-6$ & 232 & 1 Jan 2002 & 15 & 16.3 & 730 \\
& \multicolumn{5}{c}{ Nontime series float in rift } \\
\hline \multicolumn{5}{c}{$>365$} \\
\hline
\end{tabular}

* Float 136 did not release anchor until 10 days after schedule.

the Tadjura Spur and the Pinnacles (which are shallower than the float).

Only one float is available for each of the next two releases, in May and July 2001 (Figs. 10c, d). Float 1-2 initially drifted eastward, then southeastward and crossed the southern rift wall through the Pinnacles about two weeks after release, at nearly the same time and location as float $1-1$. Float temperature was $18^{\circ}-$ $19.5^{\circ} \mathrm{C}$ along its track as it left the rift. Float 2-3, which was released after the three previous floats had left the rift, meandered around the release site, then drifted westward then southward out of the rift 44 days after deployment. ${ }^{3}$ Its temperature is initially several degrees cooler $\left(15^{\circ}-16^{\circ} \mathrm{C}\right)$ than float $1-2$, but increases to a maximum of $\sim 17^{\circ} \mathrm{C}$ as the float drifted westward deeper into the rift (between days 40 and 50), then to $17^{\circ}-18^{\circ} \mathrm{C}$ as the float drifted southward through Pinnacles Gap (between days 50-60).

The next two floats, $1-4$ and 2-4 (Figs. 10e,f), were both released during the summer REDSOX cruise. Both floats initially drifted westward, as in the first release. Float 1-4 meandered within the rift for more than three months, but float 2-4 left much more quickly, within two weeks. Temperature measured by float 1-4 in the western rift was cooler $\left(17^{\circ}-18^{\circ} \mathrm{C}\right)$ than floats deployed earlier at the same site, consistent with the colder and less saline water found there at the float depth during the summer cruise (Fig. 4). Temperature along this track began to increase slowly beginning

\footnotetext{
${ }^{3}$ This float did not release its anchor for the first 10 days.
}

around day 30 (not shown), and exceeded $18^{\circ} \mathrm{C}$ around day 90 (untracked portion; around 1 December 2001) and remained above $18^{\circ} \mathrm{C}$ until after day 112 , probably indicating the injection of new winter outflow water into the rift. As in the two previous releases from site 2, float 2-4 initially measured cooler temperatures than its partner float $1-4,15^{\circ}-16^{\circ} \mathrm{C}$, which increased to $16^{\circ}-$ $17^{\circ} \mathrm{C}$ when the float began drifting southward out of the rift. This float left the rift at about the same time and location as float $2-3$, released about two months earlier. Both floats 1-4 and 2-4 left the rift through Pinnacles Gap.

The next release, in November 2001, was near the beginning of the strong winter outflow season (Figs. $10 \mathrm{~g}, \mathrm{~h})$. Float $1-5$ initially measured temperatures $17^{\circ}-$ $18^{\circ} \mathrm{C}$, but as it drifted slowly eastward toward the $\mathrm{NC}$ exit, temperature increased to $18^{\circ}-19^{\circ} \mathrm{C}$ around day 20, and the float abruptly turned southward and crossed out of the rift through Pinnacles Gap about 30 days after release. This was just 20 days before the previous float, 1-4, also left the rift through Pinnacles Gap. Its partner, float $2-5$, remained nearly stationary for the first 10 days after release (making two very small cyclonic loops, not visible at this scale), then drifted directly southward and out of the rift through Pinnacles Gap in less than two weeks. Temperatures immediately after release were quite cool, $14^{\circ}-15^{\circ} \mathrm{C}$, but increased slightly to $16^{\circ}-17^{\circ} \mathrm{C}$ as the float drifted southward south of the rift.

The last time series float we have available in the rift is float 2-6 (Fig. 10j), which was released on 1 January 2002. Like other floats deployed from this site, it drifted quickly southward and out of the rift, and measured moderately cool temperatures, $16^{\circ}-17^{\circ} \mathrm{C}$. For completeness, we include in Fig. 10 the only other float that was deployed within the rift, float 171 , which was released during the winter cruise near the southern wall of the rift (Fig. 10i). This float meandered within the rift for its entire 1-yr mission, and surfaced not far from its release site. While continuous tracking was not possible, inspection of the individual time of arrival records indicates that this float was freely drifting and not stuck to the bottom. Temperature was initially about $18^{\circ} \mathrm{C}$, and ranged between $17^{\circ}$ and $20^{\circ} \mathrm{C}$. Maximum temperature was observed between days 50 and 100 (May-June 2001), when the float was the farthest east in the rift, and coolest around day 175 (September 2001). By the end of the record (March 2002), temperature had increased again to $18^{\circ}-19^{\circ} \mathrm{C}$.

Several consistent features of the circulation in and around the rift emerge from these float tracks. First, floats deployed at the western time series site tend to 
remain trapped in the rift for longer periods: average residence time within the rift, defined as the elapsed time between release and crossing the southern rift wall, was 56 days for TS 1 , as compared with 34 days for TS 2. This difference most likely results from the more confining effect of the southern rift wall in the western rift. Second, there is some evidence of spatially coherent oscillatory zonal motion in the rift, but there is no apparent correlation with season: floats released at both time series sites initially drifted westward during the winter (float 1-1, 2-1) and summer (1-4, 2-4) releases. Third, all of the nine time series floats left the rift by drifting southward over the southern rift wall, and seven of these did so through the Pinnacles Gap. This seems to be the main pathway by which outflow water at this level escapes from the rift. While there is evidence of variability, the main impression from these float trajectories is of a prevailing southward or southwestward current that sweeps outflow water from the entrance of the rift southward along the slope of the Tadjura Spur and into the southwestern GOA. Fourth, all of the floats released from TS 2 initially measured temperatures several degrees cooler than their partners to the west, strong evidence that they were deployed in or east of the strong front separating new outflow water from Gulf of Aden thermocline water. As these floats drifted westward and/or southward, temperature had a tendency to increase, suggesting that they were being entrained into the stream of outflow water escaping through Pinnacles Gap. This is counter to what was expected: TS 2 was placed to release floats into the new outflow water exiting from the NC: apparently the outflow water exits the NC mainly to the west of TS 2 (see more discussion below).

\section{Discussion}

\section{a. Equilibration depths of RSOW}

In general terms, sinking of Red Sea outflow water to the bottom of the Tadjura Rift would be somewhat unexpected, given that it flows over the very shallow Hanish Sill (sill depth is about $150 \mathrm{~m}$ ) and therefore comes in contact with and could entrain much lighter upper ocean water. This would seem to make it difficult for product waters to be dense enough to reach the bottom (Price and O'Neil Baringer 1994). This was certainly the case during REDSOX: the Red Sea outflow water in the channels was not dense enough to sink to the seafloor at the bottom of the Tadjura Rift, in summer or winter. However, hydrographic data collected by Siedler (1968), and mooring data from Murray and Johns (1997), indicate that at least occasionally, the out- flow water in the $\mathrm{NC}$ in winter is denser than the bottom water in the rift, and thus may be capable of sinking to the seafloor once it reaches the $\mathrm{NC}$ exit, provided that entrainment is not too strong as the outflow spills into the deep rift.

One possible explanation for the variations in outflow density observed in the NC during winter is variability in the density of the outflow source waters. This explanation is not the most likely for two reasons. First, variability in the source water characteristics is small relative to variability observed in the NC. The source waters come from a large reservoir of nearly isothermal $\left(\sim 22^{\circ} \mathrm{C}\right.$ ), isohaline (40.5) Red Sea Water that extends from $\sim 80 \mathrm{~m}$ to the bottom of the Red Sea (Maillard and Soliman 1986). Siedler (1968) and Quadfasel and Verch (1987) have shown that the $T$-S characteristics of this water mass vary little on seasonal or shorter time scales. At the northern end of BAM Strait (Hanish Sill), Murray and Johns (1997) observed very small salinity variations during the strong winter outflow season: salinities were always in the range 40.5-40.7, which is equivalent to $0.15 \mathrm{~kg} \mathrm{~m}^{-3}$ if not compensated by temperature changes. This density change is considerably less than the $\sim 0.4 \mathrm{~kg} \mathrm{~m}^{-3}$ peak-to-peak variations in maximum density observed in the $\mathrm{NC}$ mooring data described in section 3b above. Second, Price and O'Neil Baringer (1994) found that product water density was remarkably insensitive to source water density using a one-dimensional streamtube model of the Mediterranean Sea outflow, where $\partial \rho_{\text {prd }} / \partial \rho_{\text {src }}=0.15$. In other words, to obtain a product water that was $0.1-0.2 \mathrm{~kg}$ $\mathrm{m}^{-3}$ more dense would require the source water to be $0.7-1.3 \mathrm{~kg} \mathrm{~m}^{-3}$ more dense, which is highly unlikely in light of the observations of the Red Sea source waters described above.

A more likely explanation for the variability in outflow density in the $\mathrm{NC}$ during winter is intraseasonal variability of outflow transport. In addition to the strong seasonal cycle in outflow transport at Perim Narrows, Murray and Johns (1997) measured large transport fluctuations during the winter season, with typical amplitude $\pm 0.2 \mathrm{~Sv}$ around the winter mean value of 0.6 Sv. On five occasions during one winter season, outflow transport increased to $>0.9 \mathrm{~Sv}$, which is $50 \%$ larger than the mean winter transport. This variability was closely correlated with wind forcing on scales of days to one month. The Murray and Johns moored observations farther downstream in the NC indicate a correlation between surges in outflow currents and outflow density. Figure 7 shows records of temperature, salinity, potential density and along-channel speed $30 \mathrm{~m}$ above the bottom between early April and late November 

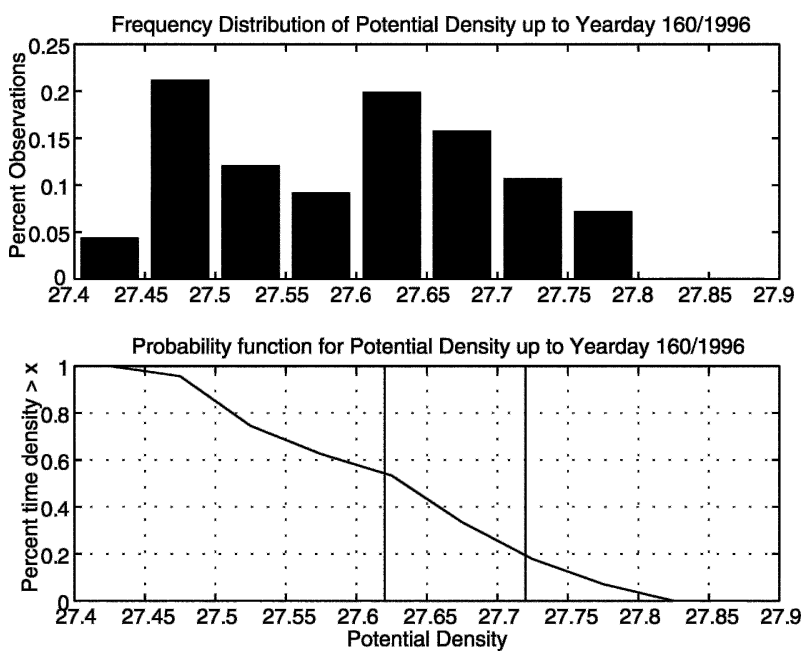

FIG. 11. (a) Frequency distribution for potential density observed $30 \mathrm{~m}$ off the bottom in the NC during winter 1996 (up to yearday 160, see Fig. 7); (b) probability distribution for potential density based on (a). The potential density in the bottom of the Tadjura Rift during the winter REDSOX cruise, $27.62 \sigma_{\theta}$, is indicated by a vertical line, as is the density that the outflow would need to have at the mooring site in order to be at least as dense as the rift bottom water when it reached the exit of the NC. See text for explanation.

1996 from the mooring deployed in the NC. ${ }^{4}$ These 40-h low-pass filtered records show the expected seasonal cycle, with strong downchannel currents $\left(>50 \mathrm{~cm} \mathrm{~s}^{-1}\right)$ in late winter decreasing to near zero, and even weakly reversing, during summer, then increasing again in early winter. Water properties follow a similar seasonal cycle (see Murray and Johns 1997).

Of interest here is the late winter period at the beginning of the record, up to yearday 160 (mid-June), when outflow currents were strong, indicative of winter conditions. During this two-month period, fluctuations in potential density of the outflow (caused mainly by fluctuations in salinity) were positively correlated with outflow speed. Correlation coefficient between density and speed for this part of the time series is 0.82 . While it is not possible to estimate outflow thickness or transport from this single mooring, it seems plausible that the variability in outflow speed is indicative of transport variability, and that both are leading to changes in outflow density. The same applies in the southern channel, where the correlation coefficient between outflow speed and outflow density was also 0.82 .

Figure 11a shows the frequency distribution for po-

\footnotetext{
${ }^{4}$ This was the second of two contiguous deployments at this location: only the second deployment included microcats to measure temperature and salinity simultaneously with current speed.
}

tential density in the $\mathrm{NC}$ from these time series data up to yearday 160, and Fig. 11b shows the probability that potential density is greater than the values on the $x$ axis, based on the frequency distribution. During this short time period, potential density near the bottom of the $\mathrm{NC}$ at the mooring site exceeded the density observed in the bottom of the Tadjura Rift during the REDSOX winter cruise (27.62) about half $(55 \%)$ of the time. Assuming a $0.1 \sigma_{\theta}$ drop in density between the mooring site and the exit of the $\mathrm{NC}$ due to further entrainment (based on REDSOX observations; see Fig. 5), these data suggest that some outflow water exiting the $\mathrm{NC}$ would be as dense or denser than the deep rift water about $20 \%$ of the time during winter. At least some further entrainment is likely as this dense water falls over the edge of the rift wall, so if outflow water reaches the bottom at all, it would occur less than $20 \%$ of the time.

Results from the one-dimensional plume model of Price and O'Neil Baringer (1994) also support the idea of increased outflow transport leading to increased density in the outflow plume. They tested the sensitivity of the plume model to variations in initial transport, and found that higher transport resulted in a less diluted, denser product water. This same model was used by Bower et al. (2000) to simulate the Red Sea outflow and compare with the observations that were available prior to REDSOX. To simulate the confining effect of the extremely narrow $\mathrm{NC}$, the model outflow was forced to maintain a constant width of $5 \mathrm{~km}$, and to flow down a plane with uniform slope of 0.005 . When the outflow reaches $650 \mathrm{~m}$, the slope is increased to 0.07 to simulate the rift wall at the $\mathrm{NC}$ channel exit. If we run this model with the initial transport and layer thickness observed during the REDSOX winter cruise, and assume that $2 / 3$ of the Perim Narrows transport follows the NC (Özgökmen et al. 2003), the final model product water has an average of $\sigma_{\theta} 27.48$ at a depth of $713 \mathrm{~m}$. The equivalence of the predicted product water density to the observed (see Table 1) is certainly fortuitous. If we now increase the transport to maximum winter values, 0.9 , increase $\mathrm{H}$ to $150 \mathrm{~m}$ and again assume that $2 / 3$ of the transport flows down the NC, the product water equilibrates $100 \mathrm{~m}$ deeper at $814 \mathrm{~m}$, and its average density is 27.58 , which is quite close to the density in the bottom of the rift in winter, 27.62. The point of these calculations is not to try to reproduce the observations exactly; rather it is to illustrate that increasing outflow transport could lead to a product water density that approaches the density of the rift bottom water using a model that has been shown to reproduce basic characteristics of many outflows (Price and O'Neil Baringer 1994). From this result, it seems quite likely that strong surges of 
outflow transport during winter could produce a product water dense enough to reach into the deep rift and perhaps to the seafloor.

Peters et al. (2005) have suggested a process by which outflow properties can remain relatively undiluted along their descending path in the NC. They showed that the outflow layer is made up of two sublayers: a relatively isolated bottom layer, and an interfacial layer above. Salinity in the bottom layer decreased more slowly along the NC than for the total outflow layer, and entrainment of lighter, fresher overlying water was confined mainly to the interfacial layer. It seems reasonable to assume that, as transport, and plume layer thickness increase, the bottom layer of the outflow may become even more isolated from mixing with the overlying water. Thus the deepest outflow water in the channel may preserve much of its high density from its source all the way to the channel exit, especially when transport is large.

One important unresolved question is how much entrainment occurs as the densest outflow water spills down into the deep rift. This is difficult to address with the observations presently available, but some evidence suggests that the effect of this final step of entrainment in changing the properties of the densest outflow water might be minimal. Recall that the density of the background fluid at the depth of the NC exit $(\sim 800 \mathrm{~m})$ is only slightly less than the density of the water in the deep rift (see Fig. 6), which means that the entrained water may have a density only slightly less than the outflow itself. Also, a narrow channel at the end of the NC (see Fig. 1c) may drain the densest outflow water down into the deep rift in a narrow vein without much further entrainment.

There are other unresolved questions that remain to be addressed about how the properties in the deep rift are maintained. For example, the fact that the rift does not appear to be getting saltier with time (salinity in 2001 was less than in 1995) indicates that there must be a salt sink somewhere, and that other physical processes besides an outflow into the deep rift are involved in maintaining the properties in the deep rift. One possibility is that diapycnal mixing above the deep rift also influences the properties of the deep bottom layer. Since the REDSOX observations show that more saline water overlies the deep rift at its western end year round, vertical salt flux out of the rift would have to take place near its eastern end, possibly implying a horizontal salt flux along the axis of the deep rift. Vertical mixing may be elevated over the eastern rift, where energetic internal wave activity may be induced by the flow of mesoscale eddies over the ragged bathymetry along the rift walls. This, and other possi- bilities, including cabelling and hydrothermal activity, will be a topic of future study.

\section{b. Dynamical adjustment of outflow currents}

The results presented in section $3 c$ above indicate that the Red Sea outflow currents diminish significantly after they emerge from the confines of the NC and SC. There is no evidence of a continuous boundary undercurrent, similar to the Mediterranean undercurrent, in the Tadjura Rift. Here we present some kinematic and dynamic considerations that could explain why such a current feature was not observed.

Perhaps the most obvious explanation for the lack of a continuous undercurrent, and the sometimes-patchy distribution of salinity immediately outside the channels (see Fig. 8) is the variability in outflow transport. As discussed above, outflow transport at Perim Narrows during the winter cruise was only about half of the winter mean value, and large intraseasonal transport variations can occur in winter (Murray and Johns 1997). This suggests that outflow currents may emerge from the channel exits with variable intensity, creating discontinuous patches or blobs of equilibrated outflow water in the rift. In fact, during the REDSOX winter cruise, outflow currents at the lower end of the $\mathrm{NC}$ were observed to drop significantly during the duration of the plume survey (Peters et al. 2005).

We can crudely estimate the size of such outflow patches as follows. According to Murray and Johns (1997), transport surges, defined as time between transport minima, are about 7 days long on average. Assuming such a surge has an average transport of $0.6 \mathrm{~Sv}$ (the mean winter value), and fills a layer $\sim 300 \mathrm{~m}$ thick (based on thickness of patch at station 40; Fig. 3a), a circular patch would have a diameter of about $40 \mathrm{~km} .^{5}$ Given that station spacing during the REDSOX cruises was up to $20 \mathrm{~km}$ in the rift, perhaps it is not surprising that patches were detected but not well-resolved.

A second consideration is that when outflow currents leaving the channel exits are weak, they will be quickly overwhelmed and indistinguishable from the background circulation, which has amplitudes on the order of $5-10 \mathrm{~cm} \mathrm{~s}^{-1}$ in the deep rift, and up to $40 \mathrm{~cm} \mathrm{~s}^{-1}$ above the rift (see Fig. 8). However, it is interesting to consider some simple dynamical models that might dictate how the outflow currents evolve when they are

\footnotetext{
${ }^{5}$ See discussion below for more details on eddy scales based on local stratification. Figure $3 \mathrm{a}$ indicates some upward deviation of the isopycnals at station 40 , suggesting that the salty patch may be dynamically active, but it is difficult to determine given the lack of nearby synoptic stations.
} 
strong relative to the background flow. We suggest here that the combination of low latitude and the bathymetric configuration of the exit channels and the rift lead to a separation of the outflow current from the boundary, preventing the formation of a subsurface undercurrent along the slope.

There is considerable literature on the separation of coastal jets, and we investigate the Red Sea outflow case in the context of earlier studies. In particular, Bormans and Garrett (1989) summarized previous work on this topic, and developed a simple generalized criterion for the separation of flow through a strait into a large receiving basin. They were motivated by the observation of alternating pathways of the surface inflow through the Strait of Gibraltar into the Mediterranean Sea. At times, this inflow separates from the southern boundary and forms an anticyclonic gyre (the Alboran gyre), while at other times, the inflow does not separate but instead forms a coastal jet along the boundary.

Based on their own laboratory experiments and earlier work, they concluded that 1) for very sharp exit corners (i.e., where $R_{w} \ll W$, where $R_{w}$ is the radius of curvature of the channel wall, and $W$ is the width of the exit channel), the flow almost always separates from the boundary; and 2) for less sharp corners, separation occurs when the inertial radius is greater than the radius of curvature of the wall-that is, $U / f>R_{w}$, where $U$ is current speed and $f$ is the Coriolis parameter. Previously, Whitehead and Miller (1979) had found that 3) separation occurred when the internal Rossby radius of deformation, $R_{c}$, was greater than the wall curvature, $R_{w}$, but this result applied only to Froude numbers [Fr $\left.=U /\left(g^{\prime} h\right)^{1 / 2}\right]$, where $U$ is flow speed, $g^{\prime}$ is the reduced gravity, and $h$ is the layer thickness) of around 1. Bormans and Garrett reproduced this result, noting that when $\mathrm{Fr} \approx 1, U \approx\left(\mathrm{g}^{\prime} \mathrm{h}\right)^{1 / 2}$ and the inertial radius and deformation radius are equivalent. They generalized Whitehead and Miller's result for a wider range of Froude numbers, determining that an inertial radius greater than the wall curvature was the more general criterion for separation.

Applying these criteria to the Red Sea outflow case, it appears that the outflow currents should separate as they flow from the channel exits. First, the exit corner at the end of the SC is extremely sharp: the radii of curvature for the 300-, 400-, and 500-m isobaths ${ }^{6}$ are all less than $1.5 \mathrm{~km}$, as compared with a channel width of $>10 \mathrm{~km}$. In the deeper NC, radii for the 500-, 600-, and $700-\mathrm{m}$ isobaths are $2.8,5.5$, and $5.5 \mathrm{~km}$, but the channel

\footnotetext{
${ }^{6}$ Note that the relevant wall curvature is that at the depth near the interface between the inflowing and outflowing layers, not the curvature of the coastline (Bormans and Garrett 1989).
}

width is also $\sim 5 \mathrm{~km}$. Thus based on the first criterion listed above, the SC outflow current should separate but that from the NC may not. The inertial radius at this latitude for the outflow speeds observed at the channel exits during REDSOX, $25(50) \mathrm{cm} \mathrm{s}^{-1}$, the inertial radius is $8(16) \mathrm{km}$ for the SC (NC)-that is, 3-5 times greater than the radii of curvature in the respective channel exits. In stronger outflow conditions, the inertial radius would be even larger. Both outflow branches should thus separate according to the second criterion. The internal Rossby radius of deformation of the outflow layer, $R_{c}=\left(g^{\prime} h\right)^{1 / 2} / f$, where $f$ is the Coriolis parameter, is about $50 \mathrm{~km}$ at the channel exits (Özgökmen et al. 2003), which is much larger than the curvature of either channel exit. According to Bormans and Garrett, the latter test using deformation radius is not particularly relevant to the Red Sea outflow case since it applies only to $\mathrm{Fr} \sim 1$, and at the channel exits, $\mathrm{Fr}$ is $\sim$ $0.2-0.3$. Even by the first and second measures, however, flow separation seems inevitable except for flow speeds less than about $6(15) \mathrm{cm} \mathrm{s}^{-1}$ in the SC (NC).

Given that the flow probably separates from the boundary immediately after being injected into the rift, there is the question of reattachment. Bormans and Garrett indicate that the separated flow initially forms an inertial bubble with radius $U / f$, which can grow larger because of recirculation once the flow curves back and hits the boundary. In the Red Sea outflow case, the narrowness of the rift may disrupt the formation of such a feature. South of the SC, the rift is about $25 \mathrm{~km}$ wide at $500 \mathrm{~m}$ (depth of equilibrated outflow from the SC), while at the NC exit, the rift is only about $18 \mathrm{~km}$ at $800 \mathrm{~m}$ (depth of equilibrated outflow from the $\mathrm{NC})$. At the NC exit, where outflow speeds are generally faster, the growing inertial bubble would most likely interact with the far wall of the rift. This might be less likely to happen south of the SC because of the greater width of the rift there, but in this case, the flow may be more influenced by the large-scale eddy field since the outflow is at a depth somewhat more above the wall of the rift.

In section 3c, we showed that the RAFOS floats deployed at the exit of the NC (TS 2) initially measured temperatures several degrees cooler than new outflow water, and suggested that they were probably not released in the path of the exiting outflow currents from the NC. In light of the estimates of inertial radius above, this may not be so surprising: a current exiting the $\mathrm{NC}$ and curving westward with an inertial radius of $16 \mathrm{~km}$ will have the float release site just on its eastern edge. Further evidence that the main pathways of the exiting outflow water lies west of the float release site is the apparent sedimentary fan south of the western half 
of the NC (see Fig. 1c). The fan is small, only $\sim 5 \mathrm{~km}$ across, but a large sediment load is not expected since the outflow plume flows over generally hard rock (S. Swift 2004, personal communication). The small amount of sediment transported by the outflow along the NC may be deposited just south of the channel exit as the outflow currents decelerate. The float release site was on the eastern flank of the fan.

\section{Summary}

Hydrographic, direct velocity, and subsurface float observations have been analyzed to describe the vertical and horizontal structure of Red Sea outflow water in the western Gulf of Aden, at the location where it is first injected into the open ocean. These data were collected on two cruises, the first in February-March 2001 and the second in August-September 2001 as part of the Red Sea Outflow Experiment. This project is focused on describing the hydrography and circulation of both the descending Red Sea outflow plumes, and the equilibrated Red Sea Outflow Water in the Gulf of Aden. In this paper, we focused on the intersection of these two regimes, where the outflow waters reach neutral buoyancy and enter the open ocean. Specifically, we have addressed the questions: 1) What are the initial equilibration depths of RSOW in the western Gulf of Aden during strong (winter) and weak (summer) outflow conditions, and, in particular, does RSOW sink to the seafloor in the Gulf of Aden? 2) How are the initial pathways of the multiple layers of RSOW influenced by topography and the background circulation? and 3) Does the equilibrated RSOW form a boundary undercurrent similar to other marginal sea outflows (e.g., the Mediterranean Undercurrent) upon injection into the open ocean?

Over $200 \mathrm{CTD} / \mathrm{LADCP}$ profiles were obtained on each of the two cruises to the area. The shipboard surveys included sections along and across the descending outflow plumes, which are steered along two distinct bathymetric channels between Bab el Mandeb Strait and the continental shelf break. In addition, 53 acoustically tracked RAFOS floats were deployed in several settings at the mean depth of the RSOW intermediatedepth salinity maximum in the Gulf of Aden, $\sim 650 \mathrm{~m}$. The floats were tracked for $1 \mathrm{yr}$ using an array of moored sound sources. A subset of these data has been used to address the questions listed above.

The results of this study can be summarized as follows.

1) During the winter cruise, when outflow transport was large, the outflow waters reached neutral buoyancy where the bathymetric channels empty into the deep Tadjura Rift. Three distinct intermediatedepth salinity maxima were identified in the rift, each associated with a different branch of the outflow plume. The equilibrated salinity maxima ranged in salinity from 38.8 to 39.2 , in depth from 400 to $800 \mathrm{~m}$, and in potential density from 27.00 to $27.48 \sigma_{\theta}$. The northern channel was the source for the most saline, deepest and densest salinity maximum. This is consistent with previous results that indicated that there is less mixing by turbulent entrainment in this channel.

2) During the summer cruise, outflow currents were lower but not zero. The outflow water reached neutral buoyancy somewhat upstream of the channel exits, with lower salinity, temperature, and potential density in comparison with winter.

3) Outflow water was not dense enough to sink into the deep Tadjura Rift at the time of the two cruises in 2001, but analysis of historical hydrographic and mooring observations indicates that outflow water as dense or denser than the bottom water in the rift may exit the northern channel about $20 \%$ of the time during winter. Whether this densest outflow water at the channel exit can reach the seafloor depends on subsequent entrainment as the outflow spills into the rift: weak background stratification and the presence of narrow channels in the rift wall may prevent significant entrainment during the final descent.

4) There was no evidence of a boundary undercurrent transporting equilibrated outflow water along the slope of the rift or gulf, as had been hypothesized by Bower et al. (2000). This is explained by considering the large variability in outflow transport during the strong winter outflow season that may result in blobs or patches of relatively undiluted outflow water rather than a continuous boundary current. Furthermore, application of several criteria for separation of a coastal jet exiting a channel indicates that the outflow currents should separate from the boundary upon leaving the bathymetric channels and may not be able to reattach because of the complex bathymetry.

5) The shallowest equilibrated salinity maximum, which exits the southern channel at about $400 \mathrm{~m}$, lies above the walls of the Tadjura Rift. Its spreading pathway along the continental slope of Africa was highly influenced by a strong cyclonic eddy located in the western Gulf of Aden during the winter cruise, which had speeds as high as $40 \mathrm{~cm} \mathrm{~s}^{-1}$.

6) Hydrographic and float observations revealed that the two deeper salinity maxima, at nominal depths of 600 and $800 \mathrm{~m}$, are initially more confined by the 
walls of the Tadjura Rift. Waters associated with both maxima are generally swept southward out of the rift through gaps in the southern rift wall, and then along the continental slope of Africa, although the deepest maximum also extends eastward along the axis of the rift. Thus the high-salinity vein along the continental slope observed by Bower et al. (2000) in historical hydrographic data appears to be the result of a quasi-persistent southward flow in the western gulf rather than a self-maintained boundary undercurrent.

A number of intriguing questions remain to be addressed concerning the initial spreading and transformation of RSOW in the western Gulf of Aden. How are the properties in the deep Tadjura Rift maintained in light of its isolation below $1100 \mathrm{~m}$, and the occasional injection of dense outflow water? The equilibrated RSOW appears to lose its initial $T-S$ characteristics quickly as it moves away from the channels. The multiple layers of equilibrated RSOW in the far western gulf are replaced by a single broader salinity maximum farther east. What are the roles of vertical and horizontal mixing in modifying the equilibrated outflow water and altering its vertical distribution? What is the origin of the mesoscale eddies that appear to have an important influence on the spreading pathways of RSOW once it escapes from the Tadjura Rift? These and other questions will be the subject of future investigation using the Red Sea Outflow Experiment observations.

Acknowledgments. The authors gratefully acknowledge the captains and crews of the R/V Knorr and R/V Maurice Ewing for their support of the REDSOX field program. Many technical and research associates participated in the collection and processing of the REDSOX datasets, and we gratefully acknowledge their skill and dedication to the project. We also thank S. Swift (WHOI) and P. Huchon (Geosciences Azur) for their assistance in making the French multibeam bathymetric data available for our use, without which this study would have been much more difficult; $\mathrm{H}$. Furey skillfully and patiently processed the float data and provided valuable assistance in figure preparation. This work was supported by the U.S. National Science Foundation under Grants OCE-9818464 (WHOI) and OCE-9819506 (RSMAS).

\section{REFERENCES}

Ambar, I., and M. R. Howe, 1979a: Observations of the Mediterranean outflow. Part 1: Mixing in the Mediterranean outflow. Deep-Sea Res., 26, 535-554.

$\ldots$, and $\_$1979b: Observations of the Mediterranean out- flow. Part 2: The deep circulation in the vicinity of the Gulf of Cadiz. Deep-Sea Res., 26, 555-568.

Beal, L. M., A. Ffield, and A. L. Gordon, 2000: Spreading of Red Sea overflow waters in the Indian Ocean. J. Geophys. Res., 105C, 8549-8564.

Bormans, M., and C. Garrett, 1989: A simple criterion for gyre formation by the surface outflow from a strait, with application to the Alboran Sea. J. Geophys. Res., 94C, $12637-$ 12644.

Bower, A. S., H. D. Hunt, and J. F. Price, 2000: Character and dynamics of the Red Sea and Persian Gulf outflows. J. Geophys. Res., 105C, 6387-6414.

—, D. M. Fratantoni, W. E. Johns, and H. Peters, 2002: Gulf of Aden eddies and their impact on Red Sea Water. Geophys. Res. Lett., 29, 2025, doi:10.1029/2002GL015342.

Candela, J., 2001: Mediterranean Water and Global Circulation. Ocean Circulation and Climate: Observing and Modelling the Global Ocean, G. Siedler, J. Church, and J. Gould, Eds., Academic Press, 419-430.

Fedorov, K. N., and S. L. Meshchanov, 1988: Structure and propagation of the Red Sea water in the Aden Gulf. Oceanology, 28, 357-363.

Furey, H. H., A. S. Bower, and D. M. Fratantoni, 2005: Red Sea Outflow Experiment (REDSOX): DLD2 float data report, February 2001-March 2003. WHOI Tech. Rep. 2005-01, Woods Hole Oceanographic Institution, $133 \mathrm{pp}$.

Hébert, H., L. Audin, C. Deplus, P. Huchon, and K. Khanbari, 2001: Lithospheric structure of a nascent spreading ridge inferred from gravity data: The Western Gulf of Aden. J. Geophys. Res., 106B, $26345-26363$.

Johns, W., H. Peters, R. Zantopp, A. S. Bower, and D. M. Fratantoni, 2001: CTD $/ \mathrm{O}_{2}$ measurements collected aboard the R/V Knorr, February-March 2001: REDSOX-1. University of Miami RSMAS Tech. Rep. 2001-01, University of Miami, $455 \mathrm{pp}$.

Madelain, F., 1970: Influence de la Topographie du fond sur l'Écoulement Méditerranéen Entre le Détroit de Gibraltar et le Cap Saint-Vincent. Cah. Océanogr., 22, 43-61.

Maillard, C., and G. Soliman, 1986: Hydrography of the Red Sea and exchanges with the Indian Ocean in summer. Oceanol. Acta, 9, 249-269.

Mecking, S., and M. J. Warner, 1999: Ventilation of Red Sea Water with respect to chlorofluorocarbons. J. Geophys. Res., 104C, $11087-11097$.

Morcos, S. A., 1970: Physical and chemical oceanography of the Red Sea (RV). Oceanogr. Mar. Biol., 8, 73-202.

Murray, S. P., and W. Johns, 1997: Direct observations of seasonal exchange through the Bab el Mandab Strait. Geophys. Res. Lett., 24, 2557-2560.

Osman, M. M., 1985: Water exchange between the Red Sea and Gulf of Aden. Simp. Int. Sobre Las Areas De Afloramiento Mas Importantes Del Oeste Africano (Cabo Blanco Y Benguela), Vol. 1, Barcelona, Spain, 205-212.

Özgökmen, T. M., W. E. Johns, H. Peters, and S. Matt, 2003: Turbulent mixing in the Red Sea outflow plume from a highresolution nonhydrostatic model. J. Phys. Oceanogr., 33, 1846-1869.

Patzert, W. C., 1974a: Seasonal reversal in Red Sea circulation. L'Oceanographie Physic de la Mar Rouge, CNEXO, 55-89.

_ 1974b: Volume and heat transports between the Red Sea 
and Gulf of Aden, and notes on the Red Sea heat budget. L'Oceanographie Physic de la Mar Rouge, CNEXO, 191-201.

Peters, H., and W. Johns, 2005: Mixing and entrainment in the

Red Sea Outflow Plume. Part II: Turbulence characteristics. J. Phys. Oceanogr., 35, 584-600.

,-- A. S. Bower, and D. M. Fratantoni, 2005: Mixing and entrainment in the Red Sea Outflow Plume. Part I: Plume structure. J. Phys. Oceanogr., 35, 569-583.

Price, J. F., and M. O'Neil Baringer, 1994: Outflows and deep water production by marginal seas. Progress in Oceanography, Vol. 33, Pergamon, 161-200.

Quadfasel, D., and N. Verch, 1987: Seasonal variability of temperature in the Red Sea: XBT sections from MCS Ubena in 1985 and 1986. Institut für Meereskunde Tech. Rep. 1-87, 25 pp.

Rochford, D. J., 1964: Salinity maxima in the upper 1000 metres of the north Indian Ocean. Aust. J. Mar. Freshwater Res., 15, $1-24$.

Rossby, H. T., D. Dorson, and J. Fontaine, 1986: The RAFOS System. J. Atmos. Oceanic Technol., 3, 672-679.
Siedler, G., 1968: Schichtungs und Bewegungsverhaltnisse am Sudausgang des Roten Meeres. "Meteor" Forsch.-Ergebn. Reihe A, 4, 1-67.

_ 1969: General circulation of water masses in the Red Sea. Hot Brines and Recent Heavy Metal Deposits in the Red Sea, E. T. Degens and D. A. Ross, Eds., Springer-Verlag, 131-137. Smeed, D., 1997: Seasonal variation of the flow in the strait of Bab al Mandab. Oceanol. Acta, 20, 773-781.

Smith, W. H. F., and D. T. Sandwell, 1997: Global seafloor topography from satellite altimetry and ship depth soundings. Science, 277, 195-196.

Whitehead, J., and A. R. Miller, 1979: Laboratory simulation of the gyre in the Alboran Sea. J. Geophys. Res., 84C, 37333742.

Wyrtki, K., 1971: Oceanographic Atlas of the International Indian Ocean Expedition. National Science Foundation, 531 pp.

Zenk, W., A. Pinck, S. Becker, and P. Tillier, 2000: The Float Park: A new tool for a cost-effective collection of Lagrangian time series with dual release RAFOS floats. J. Atmos. Oceanic Technol., 17, 1439-1443. 